\title{
Una modernización importada. Consumo de artículos extranjeros en el Valle del Cauca (1850-1900)*
}

\section{Resumen}

Este artículo da cuenta de la relación que surgió entre el consumo de artículos importados y los significados que les dieron los consumidores locales. Se concentra sobre los significados de modernización, higiene y distinción social en la región del Valle del Cauca durante la segunda mitad del siglo XIX. Al final se demuestra que el largo viaje que hacían las mercancías entre los puertos europeos y norteamericanos, y el Valle, donde se combinaban diferentes modalidades de transporte y mecanismos comerciales, fue considerado una práctica moderna que adelantaron los comerciantes. Sin embargo, el consumo de importaciones no significó una entrada de lleno en la modernidad, sino la emergencia de varias modernizaciones en diferentes campos, niveles y con distintas formas de afectación en cada uno de los grupos sociales. Con todo, este es un intento por escribir una historia cultural y económica sobre una de las facetas menos conocida del comercio internacional decimonónico, dentro de un campo de investigación que viene abriéndose camino: la historia del consumo.

\section{Palabras clave}

Tesauro: Comercio internacional, exportación/importación, modernización, consumo, higiene.

Autor: Importaciones, modernidad, higiene, distinción social, Valle del Cauca, siglo XIX.

Referencia bibliográfica para citar este artículo: Arévalo Meneses, Brayhan. "Una modernización importada consumo de artículos extranjeros en el Valle del Cauca (1850 1900)". Anuario de Historia Regional y de las Fronteras 25.2 (2020): 187-219.

Brayhan Arévalo Meneses: Magister en Historia de la Universidad de los Andes. Estudiante de Doctorado en Historia Latinoamericana de la Universidad Andina Simón Bolívar, Ecuador. Código ORCID: 00000001-5885-3442. Correo electrónico: arevalo231@gmail.com.

\footnotetext{
* Esta investigación surgió durante los seminarios del programa de Doctorado en Historia Latinoamericana de la Universidad Andina Simón Bolívar, Sede Ecuador, cohorte 2019-24.
} 


\title{
An Imported Modernization. Consumption of Foreign Goods in Valle del Cauca (1850-1900)
}

\begin{abstract}
This article explains the relationship that took place between the consumption of imported articles and the meanings that local consumers gave them. It focuses on the meanings of modernization, hygiene and social distinction in the Valle del Cauca region during the second half of the nineteenth century. Finally, it is shown that the long journey that merchandise made between European and North American ports, and Valle del Cauca, where different means of transport and commercial mechanisms were combined, was considered a modern practice that merchants carried out. However, the consumption of imports did not represent a complete entrance into modernity, but the appearance of various forms of modernization in different fields, levels and with different forms of affectation in each of the social groups. In short, this is an attempt to write a cultural and economic history about one of the least known facets of international trade of the nineteenth century, within a field of research that currently makes its way: the history of consumption.
\end{abstract}

Keywords

Thesaurus: International Trade, Export/Import, Modernization, Consumption, Hygiene. Author: Imports, Modernity, Social Distinction, Valle del Cauca, 19th Century.

\section{Uma modernização importada. Consumo de bens estrangeiros em Valle del Cauca (1850-1900)}

\section{Resumo}

Este artigo explica a relação que emergiu entre o consumo de artigos importados e os significados que os consumidores locais deram-lhes. Concentra-se nos significados de modernização, higiene e distinção social na região do Valle del Cauca durante a segunda metade do século XIX. No final, mostra-se que a longa viagem que as mercadorias faziam entre os portos da Europa e da América do Norte, e o Valle del Cauca, onde diferentes meios de transporte e mecanismos comerciais foram misturados, foi considerada uma prática moderna que os comerciantes realizavam. No entanto, o consumo de importações não significou uma entrada completa na modernidade, mas o surgimento de várias modernizações em diferentes campos, níveis e com diferentes formas de afetação em cada um dos grupos sociais. Em suma, é uma tentativa de escrever uma história cultural e econômica sobre uma das facetas menos conhecidas do comércio internacional do século XIX, dentro de um campo de pesquisa que atualmente se abre caminho: a história do consumo.

Palavras-chave

Thesaurus: Comércio internacional, exportação/importação, modernização, consumo, higiene.

Autor: Importações, modernidade, distinção social, Valle del Cauca, século XIX. 


\section{Introducción}

Pasado dos días, estaba ya nuestro Telémaco vestido y acicalado por el maestro Hilario; y aunque su ropa a la moda le incomodaba y las botas nuevas lo hacian ver candelillas, hubo que sujetarse, estimulado por la vanidad. Jorge Isaac, María (Bogotá: Plantea, 2013) 78.

La llegada libre y masiva de productos industriales europeos y norteamericanos a las nacientes repúblicas latinoamericanas a mediados del siglo XIX, hizo parte del proyecto económico que adelantaron los gobiernos y los comerciantes para la consolidación del Estado nacional republicano. A través de los impuestos aduaneros a las importaciones, los gobiernos obtuvieron los recursos fiscales necesarios para cubrir sus gastos bélicos, burocráticos, pagar los intereses de la deuda pública e invertir una parte en la construcción de medios de transporte que unieron las sierras y valles con el mar.

Hoy conocemos bien los aspectos del comercio de exportaciones de materias primas que propiciaron la incorporación económica nacional al mercado mundial (valor, peso, origen y destino). Sin embargo, conocemos poco del comercio de las importaciones y mucho menos de la forma como fueron consumidas por los habitantes en las regiones.

Esta investigación aborda esa faceta menos conocida e intenta responder a la pregunta: ¿Cómo funcionó y qué significados le dieron los vallecaucanos al consumo de importaciones durante la segunda mitad del siglo XIX? Dadas las diferencias regionales del espacio colombiano y las limitaciones que implica hacer generalizaciones nacionales, esta investigación se concentra únicamente sobre el circuito comercial del valle geográfico del río Cauca, que cubría la conexión entre Buga, Palmira, Cali y el puerto de Buenaventura. (Ver mapa 1).

En la actualidad y para el caso latinoamericano, existe un creciente interés entre historiadores y antropólogos por el estudio de la cultura material y el consumo de bienes. ${ }^{1}$ Dichos estudios configuran un subcampo de investigación conocido como historia del consumo, que relacionan el consumo de bienes importados con la modernidad, la identidad y la construcción de las naciones en América Latina. Gracias a la combinación del enfoque keynesiano de la demanda, la historia cultural y los estudios de la antropología social, la historia del consumo hizo una crítica a las visiones dominantes provenientes del estructuralismo, el dependentismo y el institucionalismo, que enfocaban sus intereses en los términos comerciales del intercambio. ${ }^{2}$ Este último

\footnotetext{
${ }^{1}$ Jean-Marie Pasez, "Historia de la cultura material", La historia y el oficio del historiador. Colectivo de autores franceses y cubanos (La Habana: Imagen contemporánea, 2002).

${ }^{2}$ Véase: Arnold Bauer, Somos lo que compramos. Historia de la cultura material de América Latina, (México: Taurus, 2002) y Benjamin Orlove, The allure of the foreign: imported goods in postcolonial Latin America (Ann Arbor: University of Michigan Press, 2000) Introducción; y más recientemente Manuel Llorca, The British textile trade in South America in the nineteenth century (Cambridge: Cambridge University Press, 2012).
} 
énfasis había dejado de lado el estudio de los factores internos de la producción y los aspectos culturales, por lo cual, la historia del consumo propuso que la adquisición de artículos extranjeros no era el simple resultado indirecto de la vinculación al mercado externo, sino que los consumidores tenían agencia sobre los productos que consumían asignándoles diferentes significados. ${ }^{3}$ Así mismo, el consumo de importaciones, junto con la propiedad de la tierra, la raza, la renta y el alfabetismo, fueron determinantes para el acceso al voto y el reconocimiento de la ciudadanía. ${ }^{4}$ En consecuencia, las modernizaciones que se produjeron a partir del consumo de bienes extranjeros, estuvieron enmarcadas dentro de un proceso mayor, de modernidad política, asociado al establecimiento de la república, la concepción de ciudadanos libres e iguales y la constante búsqueda del crecimiento económico. ${ }^{5}$

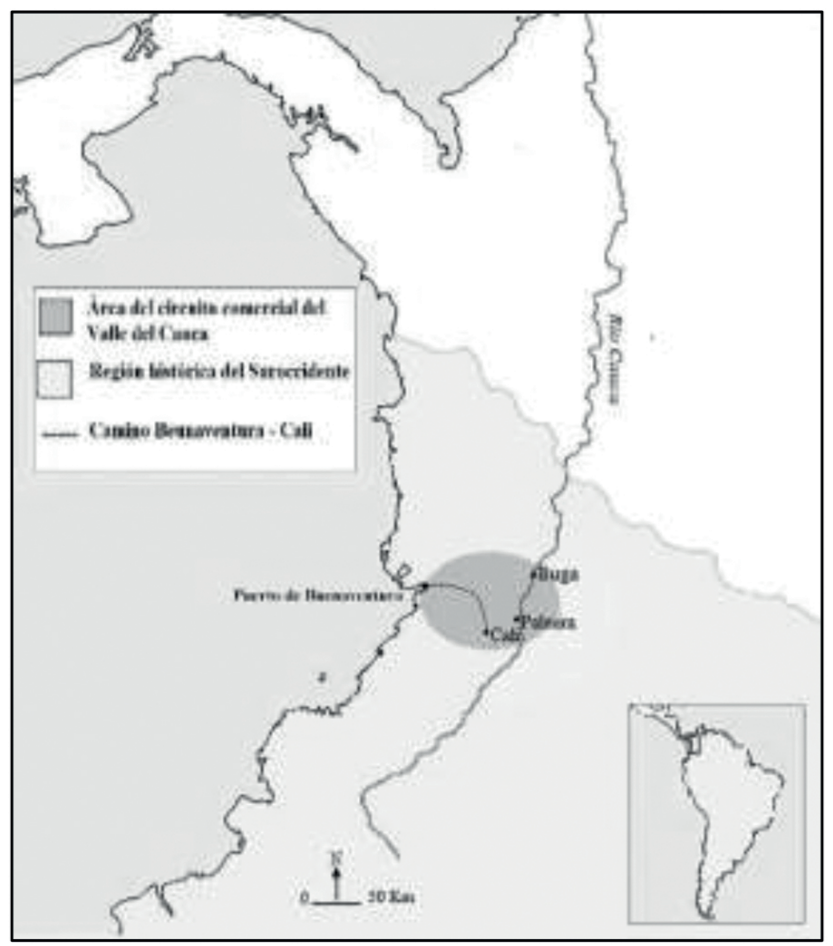

Mapa 1. Área del circuito comercial del Valle del Cauca 1850-1900. Fuente: elaboración del autor

\footnotetext{
${ }^{3}$ Los consumidores del Cono Sur entre 1810-1860 fueron el principal mercado de las casas comerciales británicas de textiles y sus gustos fueron estudiados y tenidos en cuenta por parte de los fabricantes y exportadores ingleses. Véase: Manuel Llorca, "Knowing, Adapting to, and Managing Demand", The British textile..., 91-114.

${ }^{4}$ Esta es una de las tesis de Arnold Bauer, Somos lo que compramos...,29.

${ }^{5}$ Las relaciones entre ciudadanía y crecimiento económico a partir de 1840 para el caso colombiano son señaladas por: Hans-Joachim König, "Ciudadano", Diccionario político y social del mundo iberoamericano. Iberconceptos I, dir. por Javier Fernández (Madrid: Fundación Carolina/Sociedad Estatal de Conmemoraciones Culturales/Centro de Estudios Políticos y Constitucionales, 2009) 234-246.
} 
Un trabajo que enhebra la historia del consumo con la historia cultural es el del antropólogo indio Arjun Appadurai, escrito hacia finales de la década de 1960. Aunque fue pensado para espacios y tiempos diferentes al continente americano y al siglo XIX, demuestra que las cosas tienen una vida social propia que se manifiesta a través de unos "regímenes de valor" que cada sociedad les otorga a los objetos dependiendo de su producción, condiciones de posibilidad, restricciones, formas de circulación, relaciones de poder y significados de prestigio, necesidad y deseo. ${ }^{6}$ En ese sentido, el consumo se presenta como una experiencia atravesada por varios significados y agencias. Por un lado, el amplio y diverso grupo de consumidores desde sus experiencias y deseos les asignan a los objetos unos significados particulares. Esos significados tienen la capacidad de definir, cambiar o reafirmar ideas, prácticas o representaciones al interior de las sociedades. ${ }^{7}$ Por otro lado, se encuentran los comerciantes cuya agencia hizo posible la introducción de las mercancías y a ellos se debe sumar la acción de los gobiernos que implantaron políticas económicas, sobre todo fiscales, que regularon la libertad del comercio. ${ }^{8}$

Hacia el anterior horizonte se encamina esta investigación y para ello propongo profundizar en cuatro aspectos que se corresponden con los cuatro apartados que componen este artículo. El primer apartado está dedicado a los comerciantes que fueron los agentes que trajeron las importaciones al Valle. El segundo, muestra que la importación de máquinas fue un proyecto discursivo de la modernidad con pocos efectos de transformación social. En tercero, estudia específicamente el consumo de medicamentos y productos de aseo extranjeros, que fueron asociados al concepto de higiene social y personal. Un apartado final, aborda el consumo de textiles importados que remarcaron las distancias de los diferentes grupos sociales en el Valle del Cauca y fijaron unos nuevos significados de gusto y condición social.

Las fuentes sobre las que se sustenta esta investigación están comprendidas por tres grupos. El primero lo constituyen los archivos de aduanas que se encuentran en el Archivo General de la Nación. Estos responden a las preguntas que tienen que ver con el tipo de mercancías importadas, procedencia, comercialización y transporte. Además, son la fuente para construir los gráficos y mapas de movimiento comercial para la década 1885-1894. El segundo grupo lo integran los periódicos regionales El ferrocarril, El Cauca y el Correo del Valle, donde las secciones de opinión y avisos, permiten observar las discusiones políticas y económicas que relacionaron el consumo de bienes importados con las ideas de modernidad, higiene y distinción social. Lo mismo se puede ver en el tercer grupo, donde se encuentran las obras literarias Impresiones y recuerdos (1897) del escritor, político y médico vallecaucano Luciano Rivera y la biografía El fundador Santiago Eder, un comerciante letón radicado en el Valle desde mediados del siglo XIX, escrita por su hijo Phanor Eder.

\footnotetext{
${ }^{6}$ Arjun Appadurai, "Introducción: Las mercancías y la política del valor", La vida social de las cosas. Perspectiva cultural de las mercancías (México: Grijalbo, 1991).

${ }^{7}$ Este proceso de resignificación del consumo de objetos en las sociedades que no los producen es llamado creolizacion o hibridación, porque junta dos universos culturales: el de fabricación y el de consumo. David Howes, Cross-cultural consumption: global markets, local realities (Londres: Routledge, 1996) 5-8.

${ }^{8}$ Véase: Mary Douglas y Baron Isherwood, El mundo de los bienes. Hacia una antropología del consumo, (México: Grijalbo, 1990) 71-74.
} 


\section{Los agentes de la modernización}

La voz modernidad y sus derivaciones morfológicas (moderno(a), modernizante y modernización) se usaban para notar cambios en varios aspectos de la vida y como nuevo marco histórico y político que sirvió para contener y explicar el mundo atlántico después de1808. ${ }^{9}$ Su utilización iba desde las esferas de la cultura política hasta el lenguaje utilizado en las prácticas más comunes. En el primer escenario se asociaba con el laboratorio político que intentaba establecer la república y la democracia a través de la escritura de cartas constitucionales, la instalación de cámaras legislativas, la celebración de elecciones, las reformas que abolían la esclavitud y la pena de muerte y otras que garantizaban la libertad de prensa y la separación Iglesia-Estado. En el segundo, la voz modernidad se extendió por varios aspectos de la vida cotidiana. Por ejemplo, comerciar con el exterior a través de Sociedades Comerciales fue visto como una actividad moderna, que dejaba atrás el tutelaje de los Consulados, el monopolio de la Metrópoli, la dependencia de la minería como único motor de la economía y la vinculación al mercado mundial donde participaban, legitimaban y se reconocían las naciones modernas. ${ }^{10}$

En 1857, el conservador caucano Sergio Arboleda, explicaba las ventajas de la incorporación al comercio externo a un grupo de estudiantes en uno de los principales centros educativos de la región, el Seminario de Popayán:

Nosotros no debemos fomentar aquellas artes cuyos productos obtenemos de Europa mejores y más baratos. Si queremos gastar telas finas, adornar nuestros salones con espejos y muebles elegantes o recrear nuestra vista con esculturas, cuadros y mosaicos, debemos sacar de nuestras tierras el valor equivalente en tabaco, añil, vainilla, caucho, zarzaparrilla, azúcar y mil productos de las regiones equinocciales. ${ }^{11}$

\footnotetext{
${ }^{9}$ James Sanders plantea la existencia de una "republican modernity" en el mundo atlántico que se dio exclusivamente en América Latina a mediados del siglo XIX en la cual, tanto las élites como los grupos subalternos participaron de la construcción de los diferentes proyectos nacionales. Este proceso fue liderado en el campo de la política por los "republicanos modernos" que a finales del siglo cedieron el control a los "letrados" que terminaron reduciendo las libertades de los "liberales populares" es decir, de los sectores subalternos. Véase: The Vanguard of the Atlantic World: Creating Modernity, Nation and Democracy in Nineteenth Century Latin America (Durham: Duke University Press, 2014). En el caso colombiano y más precisamente en el Caucano, este mismo autor demuestra que la alianza entre políticos liberales y grupos subalternos (colonos, indígenas, negros, trabajadores pobres y mujeres) desde 1848 hasta 1875, permitió la negociación y participación de estos últimos en la construcción del Estado nacional. Sobre todo, en los asuntos trascendentales de la tierra frente a los terratenientes conservadores. Luego que se posesionó la Regeneración, la participación de los subalternos fue atenuada, por tal razón, en este periodo el gobierno de los "letrados" se fortaleció, pero la nación se debilitó. Véase: Contentious Republicans: Popular Politics, Race, and Class in Nineteenth-Century Colombia (Durham: Duke University Press, 2004).

${ }^{10}$ Germán Colmenares, Cali, terratenientes y comerciantes. Siglo XVIII (Cali: Universidad del Valle, 1975), el cambio de sociedades coloniales a agrícolas es estudiado por el mismo autor en "El tránsito a sociedades campesinas de dos sociedades esclavistas en la Nueva Granada, Cartagena y Popayán, 1780-1850", Huellas, n. ${ }^{\circ} 29$ (1990). Sobre el escenario mundial véase: Immanuel Wallerstein, El moderno sistema mundial (México: Siglo XXI Editores, 1979).

${ }^{11}$ Citado por Frédéric Martínez, El nacionalismo cosmopolita. La referencia europea en la construcción nacional de Colombia, 1845-1900, (Bogotá: Banco de la Republica, IFEA, 2001) 149.
} 
Los agentes que hicieron posible esta nueva dinámica moderna de los intercambios fueron los comerciantes, nacionales y extranjeros, que fundaron Sociedades Comerciales. La mayoría fueron registradas en Nueva York y Londres y sus principales objetivos fueron aumentar las ganancias, diversificar las inversiones y consolidarse como un grupo social dominante. Para ello, se apropiaron del negocio de la compra y venta de exportaciones (tabaco, café, cueros, tagua y cacao) y de las importaciones (textiles, alimentos, bebidas alcohólicas, maquinaria, etc.), a través de varios mecanismos que ofrecía el libre comercio libre. Entre los principales se cuentan: el dominio del mercado de cambios, la fundación de instituciones de crédito, la compra anticipada de cosechas a los grandes y pequeños agricultores y los negocios por comisión o consignación. ${ }^{12}$ Así mismo, funcionaron agencias comerciales temporales que se establecieron a través de poderes que se registraban en las notarías locales y servían para gestionar toda clase de negocios con el respaldo de la sociedad comercial. Dichos negocios se extendían sobre la venta exclusiva de productos industriales, seguros, servicios, fletes y el envío de información comercial que incluía las tendencias de consumo locales. ${ }^{13}$ De esta manera, se consolidó una densa red comercial que se extendió por el Valle, el puerto de Buenaventura y otros puertos extranjeros como Londres, Nueva York, San Nazario, Bremen, El Callao y Guayaquil. Sin embargo, los productos importados de origen inglés y norteamericano fueron preponderantes y configuraron el $50 \%$ de las importaciones que entraron por Buenaventura como se puede ver en el mapa 2.

\footnotetext{
${ }^{12}$ En el Cono Sur y en México los mecanismos no variaron significativamente con respecto al Valle del Cauca. Véase: Manuel Llorca, "Contracts and Commissions" The British textile..., 115-140 y Adriana Corral Bustos, Estrategias de asociación para la inversión. El desarrollo del sistema de financiación en San Luis Potosí entre 1850-1900 (San Luis Potosí: El Colegio de San Luis, 2017).

${ }^{13}$ Existían poderes generales y especiales. Los primeros servían para designar un representante comercial que podía realizar una amplia cantidad de negocios y hacer de albacea en cualquier lugar. El segundo tenía un propósito comercial específico y en la mayoría de los casos se hacía para cobrar dinero y negociar con mercancías o inmuebles en lugares y con personas determinadas. Véase: Archivo Histórico de Cali (AHC), Notaria Primera, t. 31, ff. 45-49. 1885. Sobre el estudio de los gustos suramericanos por parte de los ingleses véase: Manuel Llorca, "Knowing, Adapting to, and Managing Demand..., 91-114.
} 


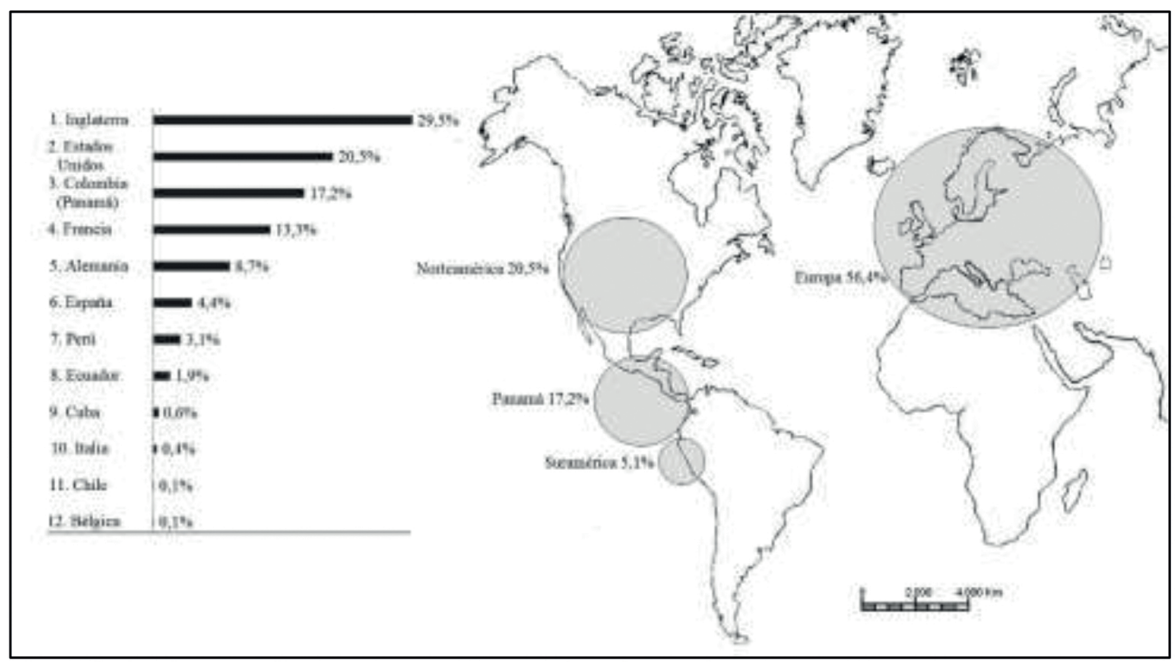

Mapa 2. Origen de las importaciones que entraron por la aduana de Buenaventura entre 1885 y 1894. Distribución construida a partir de los valores y orígenes manifestados en los cuadros de importaciones de la aduana de Buenaventura. Fuentes: AGN, SR, Aduanas Buenaventura, t. 7, 8, 9, 10; AGN, SR, Aduanas t.12, 14, 15, 17; AGN, SR, Aduanas Buenaventura-Mocoa, t. 1; AGN, SR, Ministerio de Hacienda, t. 71, 430, 431; Memoria de Hacienda 1885, Informes de Hacienda 1892, 1894, 1896, 1898. Mapa de base: IGAC. Colombia aparece como lugar de procedencia de las importaciones en la aduana de Buenaventura, porque Panamá era un puerto franco, es decir, un lugar donde se descargaban las mercancías para ser llevabas a otros lugares sin pagar impuestos.

Entre los hombres de negocios se destacaron los cónsules de Estados Unidos, el reino de Cerdeña y Perú, residentes en Cali y Buenaventura, y todos los cónsules colombianos que se encontraban en los puertos extranjeros, que no sólo dominaban la información comercial de primera mano, sino que también daban cuenta de la situación política y social del lugar donde se encontraban. Para ello hicieron un uso intensivo del telégrafo, que en el Valle se terminó de construir en $1870 .{ }^{14}$

La información encontrada en los telegramas cruzados entre comerciantes, agentes y cónsules, trata de varios asuntos relacionados con los cambios de precios, la calidad de los productos, los problemas del embalaje, las tendencias de la demanda, asuntos sobre impuestos, costumbres locales y el ambiente político a nivel regional y nacional. ${ }^{15}$ Por ejemplo, en un informe de noviembre de 1872, el cónsul de los Estados Unidos en el Valle y uno de los más grandes comerciantes, Santiago Eder, escribió al Departamento de Estado: "Las exportaciones han aumentado en la misma proporción, considerablemente con nuevos productos tales como añil y café. El tabaco que se exporta de Palmira ahora tiene los precios más altos de Europa después del de la Habana". ${ }^{16}$

\footnotetext{
${ }^{14}$ Richard Hyland, Sociedad y economía en el Valle del Cauca. El crédito y la economía, 1851-1880. t. IV. (Bogotá: Banco Popular, 1983) 218.

${ }^{15}$ Junto con los mensajes se anexaban las facturas y manifiestos de importación. Archivo Manuel María Buenaventura. BLAA, Sala R y M, c. 71, f. 5, (correspondencia 1888). AGN, SR, Aduanas Buenaventura, t. 8, f. 199-236 (1890).

${ }^{16}$ Phanor Eder, El fundador Santiago M. Eder (Bogotá: Flota Mercante Grancolombiana, 1981) 184-185
} 
En la tabla 1 aparecen las sociedades comerciales que quedaron registradas en la aduana de Buenaventura, en los contratos notariales y en los registros de almacenes y tiendas de Cali para el año 1898. Estas sociedades no solían especializarse en un solo producto, por lo cual es difícil clasificarlas de otra manera que no sea por el lugar donde tenían sus instalaciones. Por lo regular, cada una de estas sociedades tenía su propio almacén de venta de ultramarinos o un depósito para la compra de productos de exportación. Lo mismo pasaba con los médicos, que eran dueños de sus propias farmacias. De esta manera, los mecanismos modernos del comercio fueron adaptados a las condiciones locales, que trajeron consigo la emergencia de una gran cantidad de almacenes y tiendas que junto con las farmacias y boticas se diseminaron por todo el Valle. ${ }^{17}$

Tabla 1. Sociedades comerciales y principales comerciantes del Valle del Cauca en 1898

\begin{tabular}{ll}
\hline \multirow{3}{*}{ Cali } & Vicente Romero M.; Jorge Sinisterra; Roberto Zadwadzki; Luciano Umaña; \\
& Manuel Sinisterra, Naranjo \& Cía., Luis Fischer \& Cía. Francisco Rivera \\
& e Hijos. E. Gaviria \& Cía.; Restrepo y Gonzáles; Francisco Restrepo y \\
& Hermanos; Borrero y Borrero; \\
\hline \multirow{3}{*}{ Buenaventura } & Menotti \& Cía.; Otero \& Cía.; Bernardo Capurro; García \& Hijos; López \\
& \& Cía.; Ramón Payán \& Cía.; A. Pagnamenta \& Cía.; Azarías Mayolo; \\
& Hermanos Caldas; José Quilici \&Cía.; Ismael Sanclemente; Carmelo \\
& Pugliese; Primitivo Crespo Pedro Laurido; Wing Chong; Kuong; Mercado \\
& e Hijos; Jesús Román; Elías Román y José A. Baltán. \\
\hline \multirow{2}{*}{ Palmira } & Marcelino Arango; Luis Escobar; Enrique Zapata; Antonio Cifuentes; \\
& Eduardo Garcés y Bergonzoli \&Rivera. \\
\hline \multirow{3}{*}{ Buga } & Sinisterra \& Cía.; Francisco Rivera e Hijos; Botero \& Gutiérrez; Manuel \\
& Tejada e hijos; Gaviria e hijos; José María Domínguez \& Cía. y Restrepo \\
& $\&$ Mendoza
\end{tabular}

Fuentes: AGN, SR, Aduanas Buenaventura, t. 7, 8, 9, 10; AGN, SR, Ministerio de Hacienda, t. 71, 430, 431; Memoria del Secretario de Hacienda Felipe Angulo dirigida al Presidente de la Unión en el año 1885 (Bogotá: Imprenta de la Luz, 1885); Informes de Hacienda de los años:1892, 1894, 1896, 1898; Lisímaco Palau, Directorio General de Colombia. Comercial, Geográfico, Administrativo y Estadístico (Bogotá: Imprenta Nacional, 1898) 342-490; Adolfo Artehortúa, "Buga en la Regeneración, Estudios sobre la Regeneración. ed. por Lenín Flórez y Adolfo Artehortúa (Cali: Imprenta Departamental, 1987) 83-121. Lista de los almacenes, tiendas de menudeo, farmacias, boticas en Archivo Richard Hyland, Universidad de los Andes (OAD), c. 1, c. 1, ff. 107-108. Archivo Histórico de Cali (AHC), Notaria Primera, t. 31, ff. 65-68, 1884; t. 32 , ff. 280,1885 ; t. 39, ff. 13-19, 1887; t. 40, ff. 378-385, 1888; t. 41, ff. 128-129, 1888; t. 42, ff. 103-107, 1888; t. 44. Ff, 60-63, 1888; t. 67, ff. 103-109, 1894; t. 63, ff. 27-30, 1895; t. 75, ff. 6-8, 1896 ; t. 103, ff. 282-290, 1900

Todos los comerciantes del estado del Cauca fueron registrados en el censo de 1870, conformando un grupo de aproximadamente 3.100 individuos dentro de una población total de 435.000 habitantes. En realidad, eran un grupo muy reducido que apenas representaba el $0,1 \%$ de la población total, en el cual estaban incluidos tanto

${ }^{17}$ Véase: lista de los almacenes, tiendas de menudeo, farmacias, boticas, Archivo Richard Hyland. Universidad de los Andes (OAD), c. 1, c. 1, ff. 107-108. 
los que pertenecían a las sociedades comerciales, como los pequeños comerciantes que tenían negocios de "segunda clase". ${ }^{18}$ También se censaron más de 500 mujeres que atendían los puestos de comestibles y artesanías en las plazas de mercado y algunas tiendas de menudeo. ${ }^{19}$

No hay muchas dudas sobre la agencia de los comerciantes en la fundación y defensa de la idea del consumo de importaciones como una forma de modernización en el Valle del Cauca. Múltiples evidencias se encuentran en los avisos de la prensa local donde se anunciaban las mercancías recién llegadas. ${ }^{20}$ Quienes accedieron a estos productos fueron compradores de varios sectores sociales en diferentes espacios. De acuerdo con los últimos censos del siglo XIX, la ciudad más grande del Valle era Cali que contaba con unos 25.000 habitantes, seguida de Buga y Palmira con unos 15.000 cada una. Según registros de ocupación y profesiones, la mayoría de estas poblaciones se dedicaban a las labores de la agricultura y la ganadería. Mientras tanto, sólo una tercera parte se concentraba en los centros urbanos alrededor del comercio, la burocracia, las profesiones liberales, el trasporte, la artesanía y los oficios domésticos. ${ }^{21}$ Eran precisamente estos últimos pobladores urbanos quienes consumieron la mayoría de bienes importados y los que les dieron los significados de modernización, higiene y distinción social, como mostraré más adelante.

Al final de cuentas, los comerciantes funcionaron como los dinamizadores de una amplia red comercial de consumo. Esas redes fueron fortalecidas por lazos comerciales materializados en sociedades comerciales, pero también, por otros lazos que no profundicé aquí, pero que tenían que ver con matrimonios estratégicos y alianzas políticas. ${ }^{22}$ Sin embargo, su mayor alcance se concentró en la utilización de los mecanismos del comercio moderno que incluían el crédito, los cambios y las agencias, además de la instalación de varios almacenes para la venta de importaciones por el espacio vallecaucano. No obstante, se trató de una actividad económica que sólo benefició monetariamente a un pequeño grupo de comerciantes y al mismo Estado colombiano que dependió de los impuestos aduaneros para atender sus

\footnotetext{
${ }^{18}$ Este censo fue solicitado por Aníbal Galindo a las autoridades del Estado del Cauca para escribir el Anuario Estadístico de Colombia que fue publicado en 1875, véase: Alonso Valencia Llano, Empresarios y políticos en el Estado Soberano del Cauca, 1860-1895 (Cali: Universidad del Valle, 1993) 29.

19 Véase además el Censo del distrito de Pavas ubicado al norte de Cali, Archivo Richard Hyland. Universidad de los Andes (OAD), c. 3, c. 3, ff. 64- 66.

${ }^{20}$ Véase las últimas páginas del periódico El ferrocarril, donde la sección de anuncios mostraba las estrategias publicitarias que adelantaron los comerciantes en asocio con los tipógrafos: avisos con imágenes de personas alegres, vestidas al estilo francés, acompañados de los laboratorios o fábricas europeas. Así mismo, se usaba un lenguaje que invitaba a probar artículos nuevos, recién llegados y para compradores "modernos", véase: El ferrocarril, 28 agosto de 1896, Biblioteca Luis Ángel Arango (BLAA), Hemeroteca, f. 4.

${ }^{21}$ Lisímaco Palau, Directorio General..., 105

${ }^{22}$ Véase algunos ejemplos en: Frank Safford, "El comercio de importación en Bogotá en el siglo XIX: Francisco Vargas, un comerciante de corte inglés", Empresas y empresarios en la historia de Colombia, siglos XIX-XX, Carlos Dávila. Comp. (Bogotá: Uniandes, Norma, 2003). Jairo Henry Arroyo, Historia de las prácticas empresariales en el valle del Cauca (Cali: Universidad del Valle, 2006) 31-33
} 
gastos. ${ }^{23}$ Paradójicamente, el beneficio lucrativo y la modernización del comercio no se vieron reflejados en los consumidores que eran en ultimas los que mantenían a flote esta actividad. Según la visión de los comerciantes, estos consumidores participaban de forma indirecta en el proceso de modernización y se llegó a representarlos como algo opuesto. El mismo Santiago Eder se refirió a la población del principal puerto comercial del Valle sobre el Pacífico en estos términos: "la población en sí, situada sobre la isla de Buenaventura, no vale ni el terreno que ocupa; las casas son meras chozas de techos pajizos [...] semejando un pueblo más bien africano que americano". ${ }^{24}$

\section{El ruido de las máquinas y las modernizaciones del campo y los transportes}

La construcción del ferrocarril del Pacífico, la llegada de barcos de vapor y maquinaria agrícola junto con la introducción de semillas, fueron vistos como importantes avances que demostraban la inserción del Valle del Cauca al mundo industrial moderno. ${ }^{25}$ Sin embargo, se trató de un proyecto discursivo usado por las elites políticas y económicas, que veían en el comercio externo el único camino hacía el crecimiento económico. Al final, esas importaciones tuvieron un impacto reducido y no alteraron significativamente las prácticas tradicionales del transporte de mercancías y del trabajo agrícola. ${ }^{26}$ En la realidad, las importaciones de maquinaria fueron escasas comparadas con otros productos y con el gran territorio que cubrían. En la aduana de Buenaventura estos artículos fueron registrados en la clase artículos de hierro y acero compuestos por máquinas de vapor, rieles, partes de la locomotora y de barcos, trilladoras de café, máquinas de escribir, coser, imprentas, máquinas para los trapiches de azúcar, arados, picas, clavos, básculas, navajas, machetes, hachas, tijeras, entre otros. En el gráfico 1 muestra el valor de las importaciones para década 1885 -1894 donde el de la maquinaria fue de $\$ 862.000$ pesos de plata, un tercio de los textiles de algodón que fueron los productos más consumidos en esta región. ${ }^{27}$

\footnotetext{
${ }^{23}$ las aduanas contribuyeron al erario público con el $60 \%$ de los recursos desde 1860 , véase: Roberto Junguito, "Las finanzas públicas..., 110.

${ }^{24}$ Phanor Eder, El Fundador Santiago M. Eder..., 184-185.

${ }^{25}$ La fundación del periódico El Ferrocarril. Periódico industrial, literario, político y noticioso en 1878 , como órgano de difusión y seguimiento a la construcción del ferrocarril del Pacífico, evidencia las bases del proyecto modernizador. Su director, Eustaquio Palacios, fue un reconocido político y escritor vallecaucano que reunió varias discusiones en este semanario, que además de la construcción del ferrocarril integraban discusiones políticas, científicas y agrícolas. Véase también: Aimer Granados, Jurisdicción territorial, discurso modernizador y virtud cívica en Cali, 1880- 1915 (Cali: Imprenta Departamental del Valle, 1996) y Jaime Londoño, "Vapores y ferrocarril en la configuración de una región económica, 1874-1974", Formas de modernización regional en el suroccidente colombiano (Cali: Facultad de Derecho y Ciencias Sociales, Universidad Icesi, 2013)

${ }^{26}$ En una reciente investigación se plantea que el crecimiento económico en el Valle del Cauca se consolidó a partir del siglo XX, debido al despegue de la industrialización, el aumento del mercado interno y el crecimiento poblacional. Véase: Hugues Sánchez y Adriana Santos (Ed.) Buscando el crecimiento económico. Mercado de factores, industrialización y desarrollo económico en Cali y el Valle del Cauca, 1900-1950 (Cali: Universidad del Valle, 2018) 15-69. Sin embargo, ya se ha demostrado la existencia de un crecimiento económico acelerado para el periodo 1845-1873 y fluctuante entre 1875-1910. Véase: William Paul McGreveey, Historia económica de Colombia, 1830-1930 (Bogotá: Universidad de los Andes, 2015) Segunda parte.

${ }^{27}$ En esta categoría no se cuentan los artículos para el alumbrado, que también podrían pertenecer a las
} 


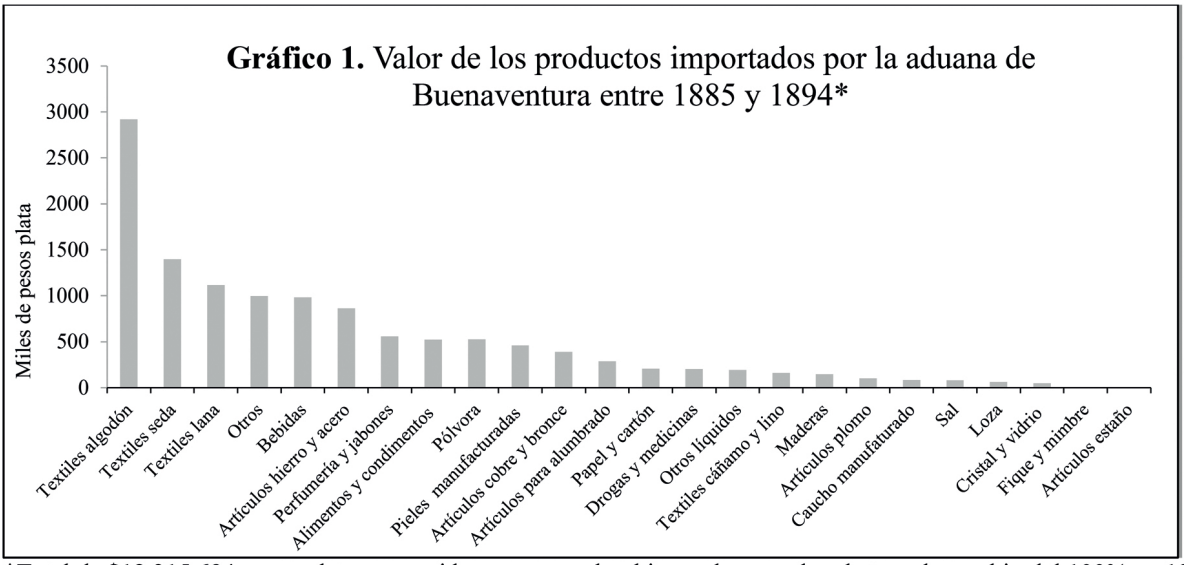

*Total de \$12.315.694 pesos plata convertidos a pesos colombianos de acuerdo a la tasa de cambio del $100 \%$ en 1892. Fuentes: AGN, SR, Aduanas Buenaventura, t. 7, 8, 9, 10; AGN, SR, Aduanas t.12, 14, 15, 17; AGN, SR, Aduanas Buenaventura-Mocoa, t. 1; AGN, SR, Ministerio de Hacienda, t. 71, 430, 431; Memoria de Hacienda 1885, Informes de Hacienda 1892, 1894, 1896, 1898.

La construcción de la vía férrea que comunicaría a Cali con el Puerto de Buenaventura, desde mediados de siglo, se convirtió en un proyecto regional más grande y ambicioso que sacaría de la condición "mediterránea" y atrasada al Valle del Cauca. ${ }^{28}$ Fue considerado por los políticos y comerciantes locales como "el gran redentor [que] renovaría la faz del Cauca" y con el ruido la locomotora daría la bienvenida al progreso. Para seguir su proceso de construcción fundaron un periódico con el nombre El ferrocarril. En sus múltiples ediciones, desde febrero de 1878 hasta diciembre de 1896, se trataron temas relacionados con su financiación, problemas y avances en las obras, costos de los fletes, asuntos relacionados con los trabajadores, itinerarios, entre muchos otros. ${ }^{29}$

En cada una de las editoriales que trataban estos temas se pueden apreciar entre líneas dos visiones. Por un lado, la gran novedad que significaba la llegada de maquinaria pesada al puerto de Buenaventura y la difícil travesía para subirla por la Cordillera a lomo de mula sobre unos caminos empinados y lodosos (ver fotografía 1). Por el otro, la llagada de un saber científico, representado por ingenieros extranjeros que traían consigo sus modernos instrumentos de medición. Contratados por el gobierno y financiados por la Junta de Accionistas, donde los comerciantes eran mayoría, los ingenieros abanderaron el "amplio frente de los "fanáticos del progreso", para quienes todo debía supeditarse a las carrileras, puentes metálicos y locomotoras". ${ }^{30}$ Todos ellos conformaron un reducido grupo social al que Frank Safford identificó como una nueva generación comercial, política y cosmopolita, que intentaba superar los valores

\footnotetext{
máquinas que mostraban una modernización en la vida cotidiana de los centros poblados.

${ }^{28}$ El ferrocarril, 14 de febrero de 1878, (BLAA) f. 1

${ }^{29}$ El ferrocarril, 12 de julio 1878, (BLAA) f. 3

${ }^{30}$ Marco Palacios. "La regeneración ante el espejo liberal y su importancia en el siglo XX", La clase más ruidosa y otros ensayos de política e historia, (Bogotá: Norma, 2002) 130-137
} 
sociales tradicionales antitécnicos. ${ }^{31}$ Para esta generación técnica, el viaje a Europa se convirtió en una etapa fundamental de su formación, porque les permitió experimentar de forma real "el mundo civilizado" y contrastarlo con el país que encontraban a su regreso. ${ }^{32}$
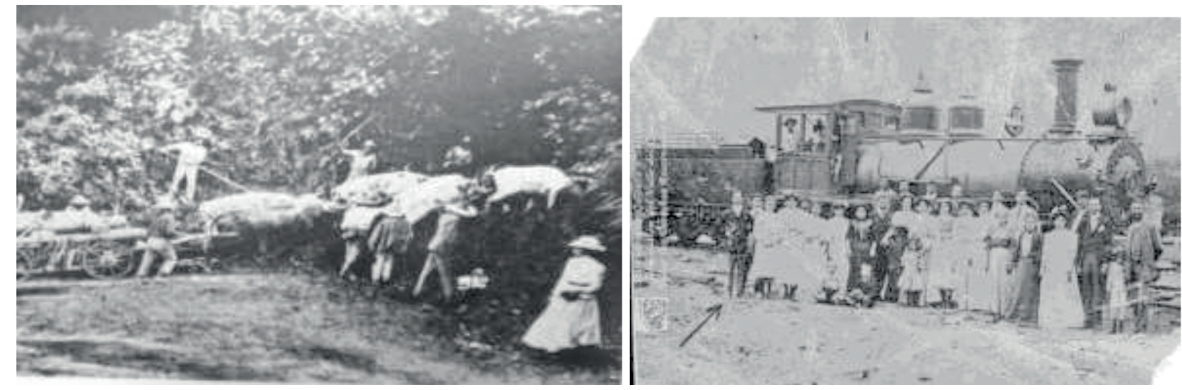

Fotografía 1. (Izquierda): Transporte de maquinaria para los trapiches por caminos de herradura de Buenaventura a Cali. [1900]. La mujer que mira la acción es Italia Ceturri de Eder, casada con Carlos Eder Benjamín, hijo de Santiago Eder. Fuente: Archivo Manuelita S.A. Fotografía 2. (Derecha): Galiciano Saavedra y acompañantes esperando la llegada del tren a la estación del ferrocarril. Dagua, 1895. Fuente: Fondo Archivo del Patrimonio Fotográfico y Fílmico del Valle del Cauca, Biblioteca Departamental Jorge Garcés Borrero (BDJGB).

Las inauguraciones de los tramos ferroviarios, la construcción de puentes y la llegada de la locomotora se convirtieron en acontecimientos sociales de gran relevancia y festejo. Estos fueron acompañados por rituales religiosos, orquestas, cabalgatas, procesiones y sirvieron de ocasión para tomar fotografías (Ver fotografía 2). De esta manera, la metáfora de la "locomotora del progreso" siempre presente en los discursos políticos y económicos, fue usada para mostrar la existencia un tiempo nuevo, acelerado y de profundos cambios. ${ }^{33}$ Sin embargo, los problemas financieros siempre fueron una constate y para finales del siglo XIX, el tramo ferroviario construido en el Valle, apenas comunicaba a Buenaventura con un poblado interior llamado Córdoba, que no llegó a cubrir ni la mitad del camino que separaba al puerto marítimo de la ciudad de Cali. Desde allí, las mercancías tenían que seguir en lomos de bestias o en champanes conducidos por bogas sobre correntosos ríos, tal y como el viajero Gaspar Mollien lo evidenció en $1820 .^{34}$

Al ruido de la locomotora se debe sumar el de los barcos a vapor que navegaban por el río Cauca, cuya primera nave inició labores a mediados de 1888, pero a los pocos meses naufragó. El bajo nivel de las aguas en verano, los bancos

\footnotetext{
${ }^{31}$ Frank Safford, El ideal de lo práctico: el desafio de formar una élite técnica y empresarial en Colombia (Bogotá: El Áncora Editores, 1898)

${ }^{32}$ Según datos de Martínez entre 1845 y 1900 viajaron a Europa por lo menos 580 colombianos y la curva de viajes por año guarda estrecha relación con las fluctuaciones del mercado de exportaciones y el orden civil interno. Frédéric Martínez, El nacionalismo cosmopolita..., 199-203.

${ }_{33}$ Javier Fernández Sebastián y Gonzalo Capellán (coord.), Lenguaje, tiempo y modernidad. Ensayos de historia conceptual (España: Globo Editores, 2011) 9-20

${ }^{34}$ Gaspar Mollien, "Por el Dagua hacia el Chocó", Viajeros extranjeros en Colombia, siglo XIX. (Cali: Carvajal, 1970) 33-45.
} 
de arena, los troncos y las rocas, truncaron el funcionamiento de este sistema de transportes que reportaba permanentemente encallamientos y averías (ver fotografía 3). No obstante, los vapores transoceánicos ingleses que visitaron el puerto de Buenaventura como parte de sus itinerarios de carga de materias primas y descarga de productos industriales, cumplieron un papel fundamental en el comercio que se aprecia en el reducido costo de los fletes. Para dar una idea basta con comparar el costo de transportar una carga de café entre Palmira y Buenaventura en 1890 que valía unos \$24 pesos y el de transportar la misma carga entre Buenaventura y Nueva York que estaba alrededor de los $\$ 4$ pesos. $^{35}$

Por su parte, los coches tirados por caballos fueron una novedad que tuvo que enfrentarse a la reducida red de caminos, el mal estado de estos y el monopolio por parte de unos pocos comerciantes. Según Phanor Eder: "los caucanos que no habían estado en el exterior ni en Bogotá, no conocían los carruajes. Santiago y los vehículos de ruedas llegaron a ser sinónimos para los Palmiranos". Cuando se presentó la primera función del cinematógrafo en Palmira en 1903, la gente vio en la pantalla a los bomberos de Nueva York en sus carros tirados por caballos y gritaron: “¿Don Santiago en su coche!” (ver fotografía 4). ${ }^{36}$

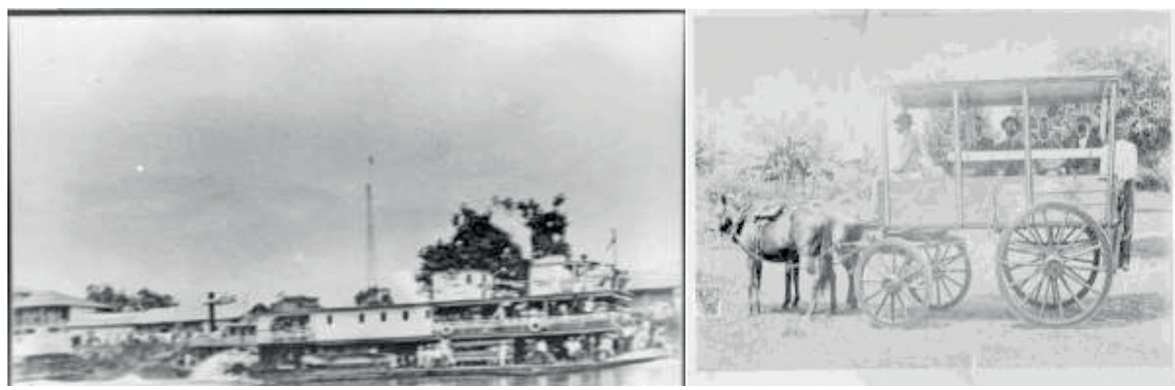

Fotografía 3. (izquierda) Barcos de vapor. Juanchito. C. 1900. Fuente:(BDJGB). Fotografía 4. (Derecha) Primer coche introducido al Valle por Santiago M. Eder, Palmira, C., 1890

La idea de unas modernizaciones importadas también se evidenció en la introducción de maquinaria agrícola. Haciendas como La Manuelita y La Rita, dedicadas a los cultivos de exportación conocieron por estos años la experiencia de la tecnificación. En esta última hacienda, el cultivo del café se inició en 1870 y su primera cosecha se hizo con semillas traídas de Jamaica que resultaron muy productivas y sus

\footnotetext{
${ }^{35}$ La Pacific Steam Navegation Company de origen inglés cubrió el comercio del Pacífico suramericano durante casi toda la segunda mitad del siglo XIX. A través de varias embarcaciones a vapor de más de 400 toneladas estableció itinerarios que visitaban los puertos de Valparaíso, Paita, El Callao, Tumbes, Guayaquil, Manta, Bahía, Esmeraldas, Tumaco, Buenaventura y Panamá dos veces por mes. Véase: AGN, SR, Aduanas Buenaventura, t. 7, f. 966; t. 10, ff. 531-532; AGN, SR, Aduanas, t, 12, f, 533-535 y El trabajo. Comercio en general, ciencias, artes, literatura, industria y avisos. Popayán, n. ${ }^{\circ} 120,24$ de enero de 1891. Desde estos puertos suramericanos la mayoría de mercancías seguían la ruta de Cabo de Hornos y otras por el ferrocarril de Panamá. Véase: Raymond Rydell. Cape Horn to the Pacific. The rise and decline of an ocean highway. (Berkeley and Los Angeles: University of California Press, 1952)

${ }^{36}$ Phanor Eder, El Fundador Santiago M. Eder..., 492
} 
ganancias sirvieron para fundar la sociedad Palmyra Coffe Plnatation Company en Londres. Para 1873, esta hacienda ya contaba con un descerezador y un despulpador de fabricación inglesa que procesaba la cosecha de 30.000 arbustos (ver Fotografía 5). Cuando se vendió la hacienda en 1878 , los arbustos llegaban a los 80.000 , con una producción de unas 100 toneladas anuales. Este cultivo se mantuvo hasta 1897 cuando fue transformado en cañaduzales, cuya rentabilidad era mayor debido a los altos precios internacionales y mejores técnicas. Por ejemplo, un trapiche en Palmira en 1880 producía casi 400 panes de azúcar ordinaria al día con molinos tirados por mulas o bueyes, mientras tanto, un ingenio, con maquinaria de vapor alcanzaba a refinar 5 toneladas diarias de azúcar (ver fotografía 6). ${ }^{37}$

Otro tipo de maquinaria agrícola importada, aunque menos tecnificada, pero que cambió los niveles de producción, fue la introducción de nuevas semillas y herramientas agrícolas de acero como machetes, alambre de púas y arados. Estos últimos fueron importados por Santiago Eder en 1868 para "para reemplazar el viejo arado español [...] fue también Santiago Eder, el primero en traer otros implementos modernos [y] enseñó a los caucanos a no tener miedo a la maquinaria". ${ }^{38}$ De acuerdo con los relatos del escritor Luciano Rivera sobre la hacienda La Isla en Buga, los tiempos de cosecha del café alteraban la paz del Cauca con: "el ruido estridente de la herramienta devastadora, la vibración siniestra del inexorable machete y las voces rudas o los dejos del bambuco que en coro entonaban algunos trabajadores". ${ }^{39}$ También se crearon sociedades democráticas y agrícolas como la Sociedad de Fomento Industrial de Cali en 1869, que promovieron la importación de semillas de tabaco Cubanas, cafetos jamaiquinos, pastos africanos, alambres de púas norteamericanos y vacas holandesas. ${ }^{40} \mathrm{Y}$ para garantizar sus beneficios publicaron en la prensa local varios artículos sobre los procesos de plantación, cultivo y cosecha. ${ }^{41}$

\footnotetext{
${ }^{37}$ Eder 469-487; 507 y 547.

${ }^{38}$ Eder 494.

${ }^{39}$ Luciano Rivera. Impresiones y recuerdos (Bogotá: Librería Nueva, 1897) t. I, 168

${ }^{40}$ El ferrocarril, 12 de julio 1878. (BLAA) Hemeroteca, f. 3; Evaristo García. Climas del Valle del Cauca (1915). En: Archivo Richard Hyland. Universidad de los Andes (OAD), c. 1, c. 2, f. 179; Alonso Valencia. Empresarios y politicos..., 160 y 204.

${ }^{41}$ Richard Hyland, Sociedad y economía en el Valle del Cauca..., 216, véase: El Correo del Valle. Periódico literario, industrial y noticioso, octubre 28 de 1897, (BLAA), Sala Raros y Manuscritos, f. 2. Muchos de esos artículos eran tomados de otros periódicos extranjeros.
} 


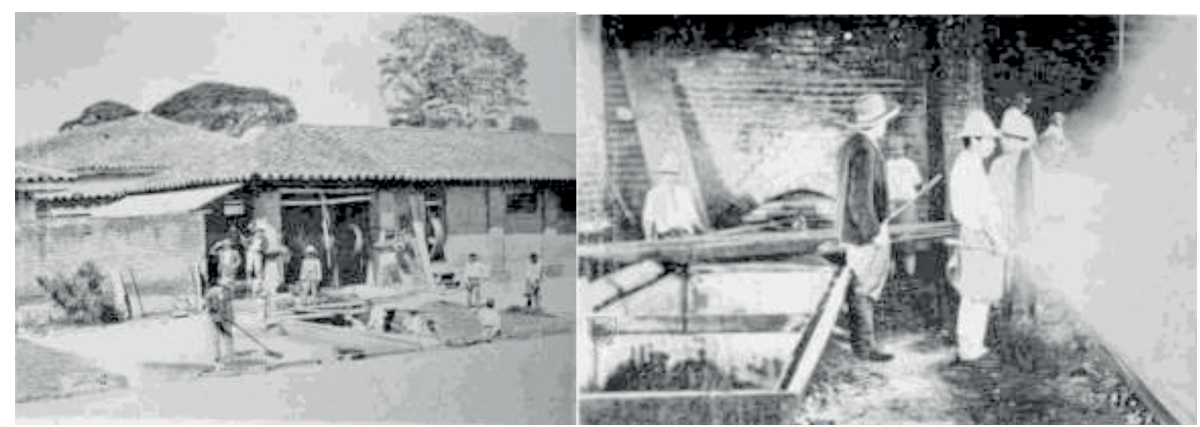

Fotografía 5. (Izquierda) Máquinas [descerezadora] y secadora de Café en la Hacienda La Rita 1891. Fotografía 6. (Derecha) Fabricación de azúcar en La Manuelita, Palmira, 1891. Fuente: (BDJGB).

De nuevo, la introducción de la maquinaria agrícola y semillas mejoradas hizo parte una idea limitada de modernización que sólo benefició la productividad de las grandes haciendas. Aunque las fuentes de aduanas no permiten ver los impactos de estas importaciones en los sistemas de trabajo, se puede decir, de acuerdo con Salomón Kalmanovitz, que siguieron reproduciendo sistemas de trabajo precapitalistas. Muchos de los peones, aparceros, agregados y arrendatarios fueron sujetados a las haciendas a través de contratos de arrendamiento sobre cosechas futuras, peonaje por deudas, pago de rentas con servicios personales y hasta salarios cancelados con mercancías importadas. $^{42}$

Todo este proceso fue sintetizado Marco Palacios, al afirmar que los proyectos económicos del estado colombiano, desde el siglo XIX, han estado atrapados por los discursos de la política económica del libre comercio sin tener muchos efectos sociales, por lo cual "ha sido posible emprender modernizaciones sin alcanzar la modernidad". Para este autor, la modernidad era un estadio de avance sobre varios frentes (político, social, cultural, económico, religiosos, científico, literario, etc.) que debía incluir a la mayoría de los habitantes. De lo contrario, era mejor hablar de modernizaciones parcializadas y sectorizadas para temporalidades determinadas que habían alcanzado desarrollos desiguales y que en muchos casos, apenas los habían esbozado. ${ }^{43}$ En el caso del Valle del Cauca durante la segunda mitad del siglo XIX los ruidos de la maquinaria y las herramientas de metal importados trajeron varios cambios y nuevos significados. Sin embargo, experimentaron serias limitaciones financieras y geográficas que repercutieron en el mantenimiento de prácticas tradicionales.

Al final, el lente con el que Palacios analiza el problema de la modernidad es acertado y permiten hacer precisiones de forma desagregada. Sin embargo, una mirada con un lente más amplio, indicaría que estas modernizaciones estaban contenidas dentro de la modernidad política que funcionó como un marco social de interpretación que permitió a los consumidores entender el mundo en términos de la consolidación

\footnotetext{
${ }^{42}$ Salomón Kalmanovitz, "El régimen agrario durante el siglo XIX en Colombia", Manual de Historia de Colombia, vol. 2. (Bogotá: Procultura, 1982), 263-270.

${ }^{43}$ Marco Palacios, “Modernidad, modernizaciones y ciencias sociales”, Análisis político, n. ${ }^{\circ 23}$ (1994).
} 
de la nación republicana y sus ideales democráticos. ${ }^{44}$ Uno de esos ideales fue el cuidado de la salud pública, por lo cual la higiene y la importación de medicinas y productos de aseo personal se convirtieron en una preocupación compartida entre del Estado, de la ciencia y de los comerciantes.

\section{Higiene y medicamentos importados}

El tránsito entre una medicina ilustrada fisiológica cuya concepción de la enfermedad y curación estaban relacionadas con la sangre, cambió a mediados de siglo XIX, hacia una medicina de tipo hospitalario conocida como anatomoclínica. Juntas fueron de influencia francesa, pero la última, combinaba la observación e interrogatorio de los enfermos con las alteraciones de los órganos y tejidos para formular tratamientos farmacéuticos. Muchos médicos colombianos viajaron a París para iniciar o repetir sus estudios de medicina y a su regreso, aplicaron las ideas médicas francesas que terminaron por imponerse en el país. ${ }^{45}$ La farmacología jugó un papel fundamental en la nueva concepción de la medicina hospitalaria como paliativo a las enfermedades producidas por agentes externos, cuyos síntomas indicaban un proceso de afectación anatómica. De esta manera, se identificaron como condiciones externas adversas la mala alimentación, los cambios de clima, el trabajo excesivo y la falta de higiene. ${ }^{46}$

A finales del siglo XIX, las políticas de higiene en el Valle del Cauca promovieron prácticas de aseo personal, limpieza de hogares y calles, control del alcoholismo, vigilancia de las enfermedades venéreas y un fuerte discurso contra la pobreza y la vagancia que, a su vez, fue asociado a unos determinismos de clase y raza. En los discursos médicos y políticos, la higiene social se convirtió en una preocupación general ante la necesidad de modernizar las costumbres y formas de vida de los sectores populares. Los adelantos farmacológicos europeos giraron en función de esta idea, prometiendo mantener la vigorosidad del cuerpo social. Concomitante al discurso higiénico se construyó otro de tipo racista que pretendía blanquear la sociedad ante la amenaza de los negros, indígenas y mestizos pobres. ${ }^{47}$ Razas propensas a producir y propagar epidemias, enfermedades venéreas, emborracharse constantemente y difundir ideas agitadoras que afectaban el cuerpo social, físico y moral de la nación. ${ }^{48}$

\footnotetext{
${ }^{44}$ Según James Sanders, la modernidad republicana latinoamericana de mediados de siglo fue una experiencia particular, novedosa y hasta más avanzada que la europea. Los valores de la fraternidad, el universalismo, la igualdad y la libertad tuvieron su mayor expresión durante este momento en el cual la modernidad se irradió desde este lado del mundo. Véase: The Vanguard of the Atlantic World..., 81-135.

${ }^{45}$ De los 102 jóvenes colombianos que viajaron a Europa a cursar estudios superiores durante la segunda mitad del siglo XIX, 45 lo hicieron en medicina, 32 en ingeniería y el resto en economía, derecho, artes y religión. Frédéric Martínez, El nacionalismo cosmopolita... 214.

${ }^{46}$ Antonio Vargas Reyes es quizás el medico más reconocido del país que repitió sus estudios de medicina en París y publicó la Gaceta de Medicina de Colombia donde se tradujeron varios artículos sobre enfermedades y salud pública. Véase Néstor Miranda, «Apuntes para la historia de la medicina en Colombia», Ciencia. Tecnología y Desarrollo, vol. 8. n. ${ }^{\circ} 1-4$ (1984).

${ }^{47}$ Véase: Craig Calhoun, "Nationalism and Ethnicity" Annual Reviews n. ${ }^{\circ} 19$ (1995) 211-239

${ }^{48}$ Carlos Ernesto Noguera, "La higiene como política", Anuario Colombiano de Historia Social y de la Cultura, n. ${ }^{\circ} 25$, (1998) 188-215. Estas ideas de agitación social no solo fueron asociadas a los grupos sociales más bajos, sino que también existió un miedo constante a la contaminación europea de "ideas
} 
La eclosión de las farmacias y boticas por todos los poblados del Valle del Cauca y la acción de los comerciantes para abastecerlas con productos renovados, permitió el acceso a los medicamentos importados a una gran cantidad de consumidores. La utilización de la prensa en este caso fue estratégica para anunciar las novedades farmacéuticas e identificar las principales enfermedades que afectaban a la población. En la sección de anuncios era común presentar los medicamentos importados como los últimos inventos de la ciencia europea y norteamericana, describir los síntomas de las enfermedades, resaltar los nombres de los fabricantes como sello de garantía y alardear de los premios recibidos en las Exposiciones Universales. ${ }^{49}$

De esta manera, dentro del proyecto nacional que idearon los políticos, comerciantes y médicos, la higiene representó un modelo de ciudadanos sanos y libres de enfermedades vergonzosas que les impedirían llevar vidas industriosas y honorables. En la edición del 4 de mayo de 1894 del semanario El ferrocarril, se pueden ver algunos alcances de estos nuevos significados higiénicos y estéticos. Un aviso publicitario en primera página aseguraba que "la mayor de las gracias concebidas a la humanidad es la Salud y de esta depende la Belleza”, más abajo aparecían publicitadas las Píldoras de Vida del Dr. Ross que decían conservar "siempre en buen estado todos los órganos del cuerpo". ${ }^{50}$

En el gráfico 1 se puede apreciar que el valor de estos productos fue similar al de la maquinaria, teniendo en cuenta que estaban compuestos por las clases "drogas y medicamentos" y "perfumería y jabones" de origen alemán, inglés y norteamericano (ver mapa 2). En general, estos artículos comprenden una categoría mayor que se podría denominarse productos de higiene y que para efectos de este análisis he divido en aquellos productos que atacaban directamente las enfermedades y los destinados al cuidado del cuerpo y la prevención. Por ejemplo, las anteriormente citadas Píldoras del Dr. Ross, hacían parte del segundo grupo de los productos que servían para prevenir enfermedades, vitaminizar el cuerpo y procurar la belleza. A este conjunto se podrían agregar los jabones, licores medicinales, polvos, elixires, ungüentos, suplementos alimenticios, bálsamos, shampoos, y algunos líquidos que contenían alcohol y perfume como la famosa Agua Florida de Murray. En este sentido, la Alcaldía y el Concejo Municipal de Cali, adelantaron campañas sanitarias, apoyadas por los médicos y boticarios, donde sugerían que el uso de artículos de aseo era necesario para mantener la salud de los ciudadanos y el orden de la ciudad. Este fue el caso del médico Evaristo García quien consideraba que "el aseo del cuerpo, los hogares y los espacios públicos, ayudaban a prevenir las enfermedades y eran prueba del grado de civilización de la ciudad". ${ }^{1}$

\footnotetext{
disociadoras" manifestadas a través de la prensa subversiva, la educación laica, la masonería, la anarquía, entre otras. Frédéric Martínez, El nacionalismo cosmopolita...,437-450.

49 En Cali había diez boticas, en Palmira siete, en Buga tres y en Buenaventura dos. Los médicos vallecaucanos fueron los dueños de las principales farmacias, entre los que se destacan Evaristo García, Enrique Garcés, Luciano Rivera y Luis Uricochea Véase: Lisímaco Palau, Directorio General..., 342-490 y Adolfo Artehortúa, “Buga en la Regeneración”..., 89.

${ }^{50}$ El ferrocarril. 4 de mayo de 1894, (BLAA), Hemeroteca, f. 1.

${ }^{51}$ Evaristo García, Climas del Valle del Cauca..., c. 1, c. 2.
} 
En este mismo grupo se encontraban los jabones de ácido fénico, azufre, alquitrán y salicílico que no sólo servían para "quitar las pecas, manchas y barros de la cara", sino para procurar el baño diario y el cuidado del rostro. ${ }^{52}$ A su vez, otros jabones y detergentes estimulaban el lavado frecuente de las ropas, trastos y habitaciones, lo que requería, indirectamente, el acceso al acueducto, alcantarillado e instalación de aguamaniles en todas las casas. Lo mismo sucedía con las cremas que prometían emblanquecer la piel y seguir el modelo de belleza europeo como se puede ver en la fotografía $7 .{ }^{53}$
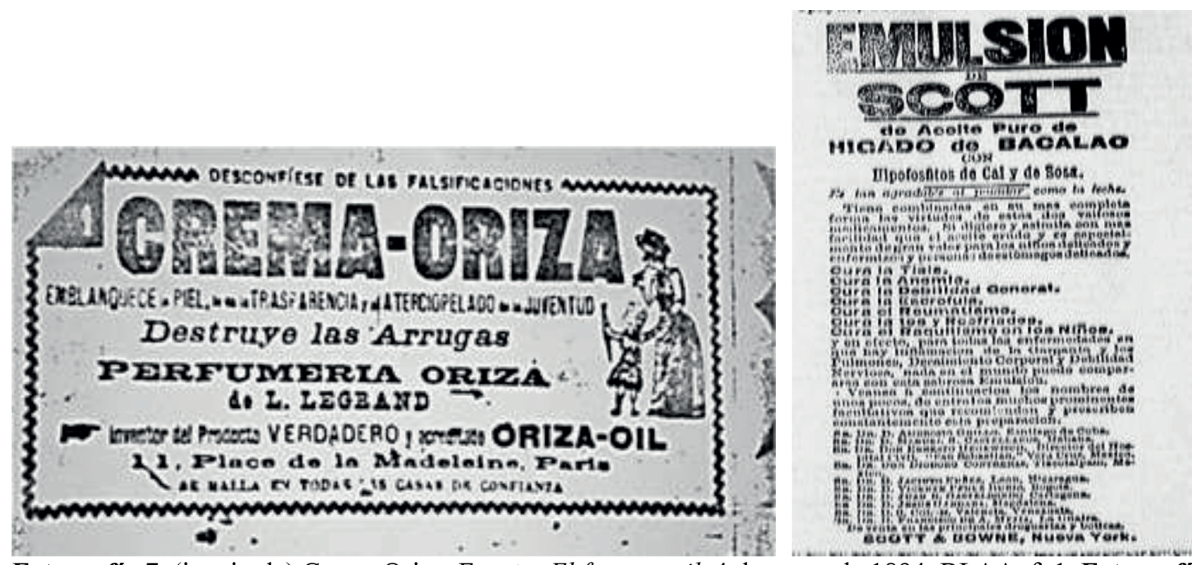

Fotografía 7. (izquierda) Crema Oriza. Fuente: El ferrocarril. 4 de mayo de 1894. BLAA, f. 1. Fotografía 8. (Derecha) Emulsión Scott. Fuente: El ferrocarril, 4 de mayo de 1894, (BLAA), Hemeroteca, f. 1.

Por su parte, la famosa Emulsión Scott que aliviaba las enfermedades respiratorias y la tuberculosis en los niños, o el Sándalo de Riquet, que curaba las enfermedades del sistema urinario y las venéreas, hacían parte del primer grupo de medicamentos que atacaban directamente las enfermedades. A este se sumaban los jarabes, capsulas, extractos, pastillas, glóbulos, soluciones y hasta cigarrillos para la gripa. ${ }^{54}$ En el primer caso, la publicidad de la Emulsión Scott decía que estaba hecha de aceite puro de hígado de bacalao con hipofosfitos de cal y de sosa, especialmente diseñada para curar la tisis, la anemia, el reumatismo y el raquitismo en los niños (Ver fotografía 8). En su diseño publicitario, como en la mayoría de los medicamentos que fueron promocionados en los periódicos, se nombraban los médicos que recomendaban el producto y en otros se encontraban los testimonios de personas que habían sido curadas. ${ }^{55}$

\footnotetext{
$\overline{52}$ El ferrocarril, 21 de enero de 1881 , (BLAA), f. 4

${ }^{53}$ Zandra Pedraza, En Cuerpo y alma: visiones del progreso y la felicidad. (Bogotá: Universidad de los Andes. 1999) 31-56; ver también: Arturo Romero, Historia de la medicina colombiana siglo XIX. (Colombia: Universidad de Antioquia, 1996) 125-142.

${ }^{54}$ Víctor García, "Hábitos perniciosos y especialidades farmacéuticas: la legislación del medicamento en Colombia durante la primera mitad del siglo XX", Historia social y cultural de la salud y la medicina en Colombia, siglos XVI-XX, Comp. Javier Guerrero, Luis Wiesner y Abel Martínez (Medellín: La Carreta y UPTC, 2010) 179

${ }^{55}$ El ferrocarril, 21 de enero de 1881, (BLAA), Hemeroteca, f. 4
} 
Adicionalmente, es importante señalar que la mayoría de medicamentos publicitados en la prensa local tenían una patente parisina o londinense que garantizaban que eran productos confiables, elaborados y probados en los modernos laboratorios científicos. Por ejemplo, las píldoras del Dr. Ayer, cuya publicidad anunciaba "curan el dolor de cabeza, estreñimiento, dispepsia, afecciones al hígado" o los Pectorales de Cereza que aliviaban las enfermedades respiratorias, tenían un patente norteamericana que constaba que habían sido ganadores del primer premio en la Exposición Universal de Chicago de $1893 .{ }^{56}$

Todo esto parece indicar, que la introducción masiva y libre de medicamentos importados al Valle del Cauca y su aparición en la prensa, funcionaron como una especie de atención médica domiciliaria que fue facilitada por las farmacias y boticas.$^{57} \mathrm{El}$ respaldo de la ciencia y los laboratorios extranjeros se convirtieron en la garantía de la salud moderna, ${ }^{58}$ con lo cual se superaron las dificultades para acceder a los pocos y costosos médicos de la región. ${ }^{59} \mathrm{Al}$ final, las medicinas y los productos para el cuidado y aseo que se vendían en las farmacias y boticas, consolidaron una modernización en el campo de la higiene personal y colectiva, aliviando una gran cantidad de enfermedades que afectaban la salud de la nación. Sin embargo, este proceso no dejó atrás las prácticas de la medicina tradicional que trataba los padecimientos con plantas o con técnicas rudimentarias y dolorosas como las sangrías. ${ }^{60}$ Un caso que se evidencia mejor la continuación de las prácticas tradicionales dentro del proceso de modernización importada es el consumo de textiles como se muestra a continuación.

\footnotetext{
${ }^{56}$ El ferrocarril, 25 de junio de 1895, (BLAA), Hemeroteca, f. 1.

${ }^{57}$ En Colombia, no existió una legislación especializada para la actividad comercial farmacéutica hasta 1914, cuando se trasladó el asunto de la venta de medicinas de los comerciantes a los médicos y a las autoridades departamentales de higiene. En consecuencia, la importación de medicinas en el siglo XIX se hizo de manera libre y sin ningún tipo de control de calidad, lo que generó falsificaciones, circulación de productos que causaban dependencia y otros sin ninguna propiedad curativa. Véase: Víctor García, "Hábitos perniciosos y especialidades farmacéuticas... 223-240.

${ }^{58}$ Algunos de esos laboratorios eran Holloway de Londres, los norteamericanos Lanman y Kemp, McKesson \& Robbins y Frederic Stearns \& Co. y los franceses Rigaud \& Company y Blancarrel y Grimault. Véase Ana María Otero, "From fashionable pianos to cheap white cotton: Consuming foreign commodities in nineteenth-century Colombia", (Dissertation Ph.D. Modern History (Latin America), University of Oxford, 2011) 168. Esto mismo pasaba en la prensa de otros países latinoamericanos. En El Nacional de Ecuador aparecieron publicidades comerciales sobre perfumes, leche antefélica para el cuidado del rostro, medicamentos de la farmacia Geneau, tratamientos para las enfermedades venéreas y para las hernias. Véase Ana Buriano, El "espíritu nacional” del Ecuador católico: artículos selectos de El Nacional, 18721875. (México: Instituto Mora, 2011) 20.

${ }^{59}$ Por ejemplo, en Cali solo hay registrados 5 médicos para una población de 25.000 habitantes. El médico Evaristo García, quien solo aparece en un anuncio de prensa, anunciaba: "Hace visitas a domicilio de las 7 a las 10 de la mañana. Oye consultas de 12 del día a las 4 de la tarde, todos los días de la semana, menos el viernes que solamente receta de las 2 a las 4 de la tarde. Los domingos no oye consultas médicas". El ferrocarril, 19 de mayo de 1882, (BLAA), Hemeroteca, f. 1.

${ }^{60}$ Victo García y Jorge Márquez, "estrategias publicitarias de medicamento en Colombia, 1850-1930", higienizar, medicar, gobernar. Historia, medicina y sociedad en Colombia, dir. Jorge Márquez. (Medellín, Universidad Nacional de Colombia, 2004) 111-126.
} 


\title{
5. Textiles importados y distinción social
}

Norbert Elías demostró que en la sociedad cortesana los cambios en las formas psicológicas del comportamiento social no siempre fueron simultáneos a los cambios en las estructuras sociales. ${ }^{61}$ Para el caso del Valle del Cauca, los cambios en los comportamientos producidos por los bienes importados fueron más evidentes que los cambios en la estructura social que siguió reafirmando su poder sobre los patrones establecidos por el antiguo régimen. Muestra de ello, es la continuación del poder basado en la propiedad de la tierra, la confesión católica, la ocupación de cargos estatales a través de clientelas, el linaje familiar y las formas distinguidas de vestir, comer y comportarse al estilo extranjero. Para mediados del siglo XIX, esto no había cambiado mucho, aunque su marco general de interpretación era republicano, y en ese contexto, la actividad comercial fue vista como una profesión práctica de gran prestigio y las formas de vestir, comer y comportarse ahora seguían los estilos francés e inglés. ${ }^{62}$

En un pasaje de la obra Impresiones y recuerdos del escritor y médico Luciano Rivera Garrido se puede evidenciar las nuevas formas de comportamiento psicológico a las que se refería Norbert Elías. A propósito de la importancia social que había tomado el comercio de productos extranjeros dentro de la sociedad vallecaucana dice:

\begin{abstract}
Aunque mi tío era muy rico, como antes lo di a entender, conservaba la tienda donde había ganado su fortuna, más por espíritu de gratitud o fuerza de costumbre, que porque en él perdurase el ánimo de especular. Allí, colocado tras de un mostrador de hechura antigua, de ésos que formaban una especie de armario muy grande, de cedro, cerrado, con anaqueles y departamentitos para objetos menudos -a estilo de botica- solía vender aún vinos españoles, especias, drogas, paños, telas de seda y cintas de terciopelo, bayetas de diferentes colores, llamadas de Castilla, para distinguirlas de las de la tierra, que tejen en el Ecuador. ${ }^{63}$
\end{abstract}

Pierre Bourdieu también hace referencia al consumo de bienes y la manera de consumirlos, afirmando que están relacionados con el capital escolar y el origen social de los consumidores. Esto quiere decir, que la adquisición de objetos podría definir las distancias entre diferentes grupos sociales, en tanto representan campos culturales diferentes. La distancia entre estos campos es lo que se define como distinción. ${ }^{64}$ Aunque la tesis de Bourdieu sobre la existencia de una lógica del gusto determinada por el capital cultural de los individuos, estaba pensada para la Francia de la segunda

\footnotetext{
${ }^{61}$ Norbert Elías, El proceso de la civilización. Investigaciones sociogenéticas y psicogenéticas (Colombia: Fondo de Cultura Económica, 1997) 10.

${ }^{62}$ Frank Safford. "Acerca de las interpretaciones socioeconómicas de la política en la Colombia del siglo XIX: variaciones sobre un tema", Anuario Colombiano de Historia Social y de la Cultura, n. ${ }^{\circ} 13-14$ (1985) 116.

${ }^{63}$ Luciano Rivera, Impresiones y recuerdos..., 173 hay que subrayar que las bayetas del Ecuador entraron al Valle del Cauca como productos extranjeros.

${ }^{64}$ Pierre Bourdieu, La distinción. Criterios y bases sociales del gusto (Bogotá: Taurus-Santillana, 1998) 100.
} 
mitad del siglo XX, podría funcionar para entender las lógicas del gusto y la distinción en la sociedad vallecaucana decimonónica. Esto se debe a que el capital escolar y el origen familiar asociado al poder económico, configuraban las posibilidades de acceso a los bienes materiales que una vez llegados a Buenaventura eran introducidos a Cali y de allí al resto del Valle para ser vendidos en los almacenes de ultramarinos.

En el Valle del Cauca, los textiles crearon dichas distinciones a partir de los regímenes de valor definidos por los materiales de fabricación, técnica, origen, marca, lugar de venta y precio. ${ }^{65}$ Para los sectores de menor nivel adquisitivo, compuestos por campesinos, jornaleros, trabajadores de obras públicas, minas y transportes, sus lógicas del gusto estaban regidas por la elección de lo necesario. Un estilo de vida que renunciaba constantemente a los beneficios simbólicos de la distinción que tenían los textiles más finos y delgados. ${ }^{66}$ Estos sólo fueron adquiridos por los grupos de mayor poder adquisitivo que jugaban a su provecho con la escasez en el mercado local y la dificultad de importarlos, haciéndolos simbólicamente más exclusivos. ${ }^{67}$

El significado del valor exclusivo de los textiles, fue construido de forma particular moviéndose entre la necesidad y el deseo. En el gráfico 1 se puede observar que los textiles de algodón fueron los artículos de mayor valor de las importaciones vallecaucanas para la década de 1884-1895 y provenían de Londres y Manchester (Véase mapa 2). Estos artículos se componían básicamente de textiles en crudo y ropa confeccionada que satisfacían las necesidades de vestuario de los trabajadores. ${ }^{68}$ Entre estos, los driles y linos, ingleses y norteamericanos, ocuparon un lugar muy importante por su durabilidad. ${ }^{69}$ Lo mismo pasaba con los textiles de lana que fueron el tercer producto de mayor valor en las importaciones, la mayoría provenientes del Ecuador y del Perú en forma de zarazas, ruanas y capisayos que atendían las necesidades y gustos de los campesinos.

Sin embargo, muchos de estos productos no renunciaban del todo a los significados de distinción que quisieron darle los grupos sociales de mediano poder adquisitivo, como los artesanos, profesionales liberales, burócratas y pequeños comerciantes, que compraron lienzos crudos de algodón y los mandaron confeccionar en forma de trajes al estilo parisino en alguna sastrería local. ${ }^{70}$ Dicho con otras palabras, los talleres de costura locales y más precisamente el oficio práctico y

\footnotetext{
${ }^{65}$ También llamados objetos “enclasantes” porque están cargados de valores estéticos, éticos y unos capitales culturales acumulados que les han asignado un grupo social cuyo estilo de vida y habitus son excluyentes y dominantes. Pierre Bourdieu. La distinción. Criterios y bases sociales del gusto..., 223. Ver también: Arjun Appadurai, "Introducción: Las mercancías y la política del valor" ..., 67.

${ }^{66}$ Mary Douglas y Baron Isherwood, El mundo de los bienes...71-74.

${ }^{67}$ Pierre Bourdieu, La distinción. Criterios y bases sociales del gusto... 379-386.

${ }^{68}$ William Paul, McGreevey, Historia económica de Colombia ... 220-223.

${ }^{69}$ Frank Safford y Marco Palacios, Colombia: país fragmentado sociedad dividida, su historia, (Bogotá: Norma, 2002) 378-379.

${ }^{70}$ Solo en Buga para 1886 había ocho talleres de sastrería conformados por directores y oficiales. Ver: Adolfo Artehortúa, "Buga en la Regeneración” ...,89.
} 
técnico del sastre, se convirtieron en los medios donde también se confeccionaba la moda europea. ${ }^{71}$

El historiador Miguel Urrutia, basado en el trabajo de Vanegas sobre la clase obrera en Bogotá publicado en 1892, calculó que una familia obrera en 1890 gastaba el $21 \%$ de su salario en vestuario, el $64 \%$ en alimentos y un $15 \%$ en alojamiento. Si se tiene en cuenta que un peón de una hacienda como la Manuelita en Palmira ganaba anualmente entre $\$ 75$ y $\$ 100$ pesos, quiere decir que invertía más o menos unos $\$ 25$ pesos en vestirse al año. ${ }^{72}$ La misma proporción se puede aplicar para los grupos de mediano poder adquisitivo, en los cuales se encontraban los burócratas que ganaban alrededor de $\$ 1.000$ pesos anuales y su inversión en vestuario era de unos $\$ 200$ pesos. $^{73}$

Por su parte, la referencia directa a los textiles y confecciones de Paris se concentró en quienes podían tener acceso a Europa, como fueron las elites políticas y económicas que realizaban el largo viaje o tenían contactos que les enviaban objetos. Según Frank Safford, "hacia mediados de siglo, las credenciales de una miembro de clase alta empezaban por incluir el hecho de tener un sastre parisiense" ${ }^{74}$ En este caso, los textiles de seda suplieron los deseos de los más adinerados que pudieron comprar estos costosos artículos que componían el segundo grupo de mayor valor de las importaciones según el gráfico 1 , pero uno de los de menor peso. ${ }^{75}$

Los modelos de vestido importados circularon a través de revistas donde se mostraban diversos y cambiantes diseños. Así, se podía apreciar en La estación, un: "periódico de modas para señoras. La mejor guía de modas. Ultimas modas de Paris", que alcanzó a tener 2.000 grabados y 48 figurines ilustrados por una suscripción que se podía hacer en el almacén de Manuel Sinisterra en Cali por $\$ 12$ pesos al año. ${ }^{76}$

Aunque se desconoce el precio exacto de las telas y las prendas de vestir confeccionadas en el mercado del Valle del Cauca, la publicidad comercial arroja algunas luces sobre su oferta. Un anuncio del almacén de los Hermanos Gonzáles en Buga decía que acababa de recibir: "A la moda de Paris. Sombreros para señoras y para hombres, los puños y cuellos de tino, las zapatillas, las bonitas corbatas y selectos perfumes [además] paños, telas de seda y lana, mantillas, blondas de seda y zarazas". ${ }^{77}$

\footnotetext{
${ }^{71}$ Arnold Bauer, Somos lo que compramos...,178. Téngase en cuenta la gran cantidad de máquinas de coser importadas al Valle de marca "Singuer" que aparecieron constantemente publicitadas en la prensa local.

${ }^{72}$ Miguel Urrutia, "Precios y salarios urbanos en el siglo XIX", La economía del siglo XIX, ed. Adolfo Meisel y Teresa Ramírez (Bogotá: FCE, Banco de la República de Colombia, 2010).

${ }^{73}$ El tesorero municipal de Cali ganaba $\$ 1.280$ pesos al año. En: Archivo Richard Hyland. Universidad de los Andes, (OAD), c. 3, c. 5, f. 137 y c. 7, f. 13.

${ }^{74}$ Frank Safford, El ideal de lo práctico..., 62, 87-94.

${ }^{75}$ Las mismas fuentes utilizadas para construir el gráfico 1 muestran el peso de los artículos, donde los productos de hierro y acero junto con los alimentos ocupan los primeros lugares, mientras los artículos de seda, caucho, estaño y fique, los últimos. Los de seda apenas alcanzan 49 toneladas en 10 años.

${ }^{76}$ El ferrocarril. 19 de julio de 1896, (BLAA), Hemeroteca, f. 1.

${ }^{77}$ El ferrocarril, 28 agosto de 1896, (BLAA), Hemeroteca, f. 4.
} 
Lo mismo pasaba con el almacén de Ramón Herrera Vélez en Cali que "acababa de recibir artículos franceses de novedad. Vestidos completos para hombre. Sobre todo sacos, levitas, [...] i todo lo necesario para un cachaco a la última moda de Paris". ${ }^{78}$ Es curioso que se tomara como referente de moda al cachaco que era un sujeto bogotano que vestía al estilo europeo y que se diferenciaba de otros coterráneos suyos ataviados con ruanas y alpargatas conocidos como guaches. ${ }^{79}$

Lo anterior demuestra que las telas y ropa confeccionada de alta y baja calidad se vendían en los mismos almacenes, por lo cual, el lugar de venta no representaba un espacio de distinción. Lo mismo pasaba con el estilo parisino que tampoco era determinante, pues siempre se podía acudir a los sastres locales. Quizás, la única forma de distinción era la tela cuya calidad marcaba la diferencia. En la fotografía 9 se pueden ver las diferencias en el vestido de los dueños de una hacienda de la región y los trabajadores del azúcar. Por un lado, es notable la distinción entre los propietarios con sus elegantes vestidos modernos, aparentemente confeccionados por algún sastre parisense o londinense, y por el otro, las ropas de los trabajadores con sombreros y ruanas de menor precio y calidad, tal vez fabricadas en los viejos y rudimentarios obrajes. $^{80}$

El vestuario como construcción cultural en la sociedad vallecaucana no sólo sirvió para establecer diferencias sociales y económicas sino para imponer diferencias raciales y políticas, que en los dos casos podían ser transgredidas. Según Arnold Bauer y Manuel Llorca, quienes estudian el consumo de textiles y sus relaciones con el poder en la América Latina decimonónica, señalan que el vestido sirvió para separar a un grupo de elite que se creía poseer los valores políticos y culturales de los blancos y mestizos, como era la ciudadanía y el derecho al voto, de aquellos que los carecían como los negros, indígenas y mulatos. Pero estas barreras fueron porosas, y siempre hubo una manera de sobreasarlas como fue el caso de los sastres, pero también se puede advertir el caso de todos aquellos que en el caluroso y húmedo clima del Valle y del Pacífico soportaron vestidos con sacos, chalecos, camisas, medias, corbatines y sombreros. ${ }^{81}$

\footnotetext{
${ }^{78}$ El ferrocarril, 19 de julio de 1878 , (BLAA), Hemeroteca, f. 4.

${ }^{79}$ Alexander Pereira Fernández, "Cachacos y guaches: la plebe en los festejos bogotanos del 20 de julio de 1910”, Anuario Colombiano de Historia Social y de la Cultura, vol. 38, n. ${ }^{\circ} 1$ (2011) 79-108.

${ }^{80}$ McGreevey muestra que el precio de los tejidos locales no estaba controlado por el mercado interno y para ello cita al cónsul británico de 1888: "El precio de las telas domésticas está, por lo tanto, en apariencia gobernado por enteramente por el de las importaciones de la misma naturaleza, aunque de superior calidad." William Paul, McGreevey, Historia económica de Colombia..., 222.

${ }^{81}$ Véase el epígrafe de este artículo, donde un joven trabajador se aguantaba la incomodidad de la ropa y el calzado en el clima del Valle. Jorge Isaac, María (Bogotá: Plantea, 2013) 78.
} 


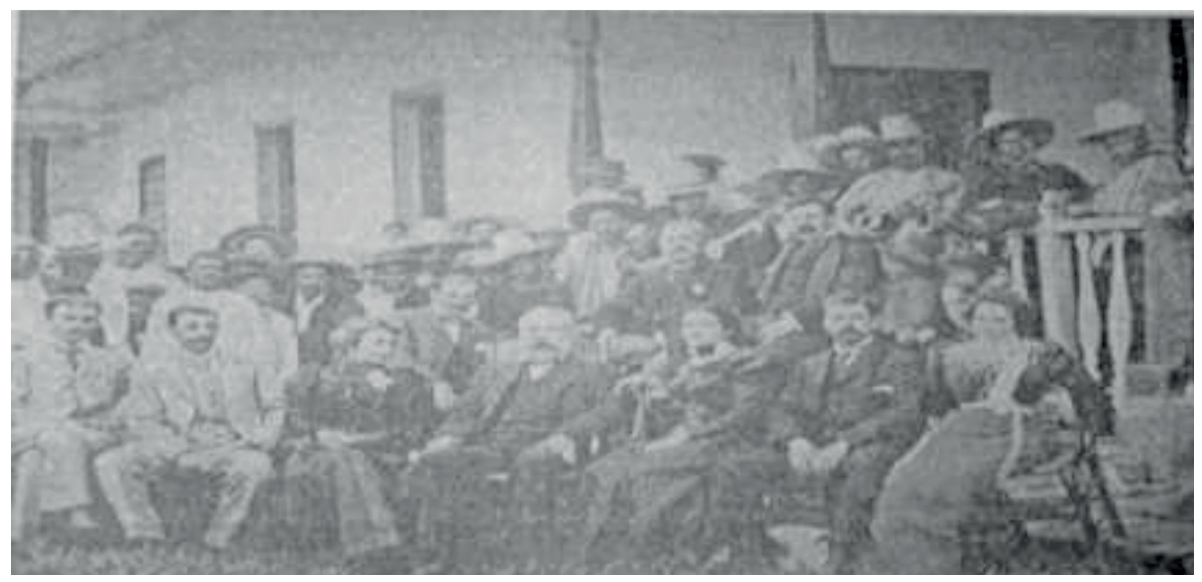

Fotografía 9. Enero de 1901 en la inauguración de la primera planta de azúcar centrifugada en la Manuelita. En el parte de abajo Santiago Eder, familiares y amigos, en la de arriba los trabajadores de la hacienda. Fuente: Phanor Eder, El fundador Santiago M. Eder... 528.

Esta distinción basada en las importaciones fue criticada por los grupos intelectuales y eescritores costumbristas conservadores que reivindicaban el legado español. Entre ellos se destacaron Ángel Cuervo, José María Vergara, Manuel Marroquín y José María Groot, quienes se burlaron constantemente de los cambios en la comida, lecturas, lenguaje, nombres, vestidos y consumo de objetos extranjeros de algunas familias liberales que, gracias al comercio escalaron de posición social y se creyeron afrancesados. Este fue el caso del "marqués de Gacharná, "un francesito de Gachancipá", que se enriqueció gracias al comercio textil llamado Gacharná and Company" ". Lo mismo pasaba con un joven caucano que se lamentaba y preguntaba:

Hoy día ¿Quién se casa? ¿Uno que cuente con tres o cuatro mil pesos al mes? ¡Infeliz! No le alcanzarán probablemente para satisfacer los deseos de esa doña moda. Señora caprichosa, que es la pesadilla cotidiana de los prudentes papás, de los maridos y tutores honrados [...] ¿Y todo por qué? Por ese incesante deseo de imitar á fulanita ó menganita con grave riesgo de la paz conyugal. ¡Maldita moda! ¡Por qué trabaste tan fuertes lazos con la mujer! Sin ti el amor no sería una idea especuladora; sería un sentimiento santo. ${ }^{83}$

\section{Conclusiones}

Las modernizaciones que se evidenciaron en el consumo de maquinaria, medicamentos, y textiles, dan cuenta de un proceso desigual, fragmentario y discontinuo, que integró a unos sectores sociales y excluyó a otros. Así mismo, la organización social, el transporte, las formas de trabajo y de producción, no se transformaron con la llegada de los productos importados y sus ruidos de modernización, algunas, por el

\footnotetext{
82 Gachancipá es un municipio de la sabana Cundiboyacense en el centro de Colombia. Véase: Frédéric Martínez, El nacionalismo cosmopolita...,190-193.

${ }^{83}$ El Cauca. Periódico literario dedicado a la juventud, 27 febrero de 1875. (BLAA), Hemeroteca, f. 2.
} 
contrario, se reafirmaron en sus viejas prácticas tradicionales.$^{84}$ De esta manera, fue posible evidenciar varias modernizaciones en diferentes campos, niveles y formas, dentro de una modernidad política republicana que asoció el consumo de textiles y medicinas con el reconocimiento de los ciudadanos. ${ }^{85}$

También quedó demostrado que el estudio de las mercancías importadas es tan significativo como el de las exportaciones, ampliamente estudiado por la historiografía y la economía. Igualmente, se observó que los efectos culturales de los bienes importados conjugan el marco interpretativo de la nación y los intercambios transatlánticos de objetos, ideas, técnicas, modas y personas. Así mismo, el modelo de conexiones culturales en forma de red conectada en el espacio regional cuestiona el sistema de intercambios desiguales entre centro y periferia establecido por los estudios económicos tradicionales. Lo que se puedo observar es que los consumidores locales le asignaron significados particulares a los bienes que consumían y estos no llegaron a imponerse como resultado indirecto del comercio internacional. ${ }^{86}$

Teniendo en cuenta lo anterior, seguir más de cerca estas relaciones entre bienes y modernizaciones, exigiría realizar un estudio más profundo de los factores que hicieron posible la producción, circulación, adaptación y venta de dichos bienes. ${ }^{87}$ Conocer las múltiples formas de transporte (vapor, ferrocarril, mula, canoa, entre otras) ayudaría a entender mejor las los significados que los consumidores les dieron a los bienes, además permitiría ampliar el estudio de mecanismos comerciales que utilizaron los comerciantes para traer todos estos productos y conformar circuitos comerciales, con lo cual se esclarecería el problema de la escasez. ${ }^{88}$ Así mismo, sería conveniente analizar los cambios de consumo dentro de los sistemas federal y centralista, el consumo visto a través de la raza y el género, el papel del Estado, la religión, la ciencia y el impacto de la importación de instituciones europeas a esta región como fueron las congregaciones religiosas, misiones educativas, ingenieros, científicos, que instalaron escuelas, universidades, instituciones de caridad e higiene, hospitales, policía, ejercito, sistemas de contabilidad pública, etc.

\footnotetext{
${ }^{84}$ Saurabh Dube señala para el sur asiático que: "todos los que viven en un momento de modernidad no son necesariamente modernos", en: "Otras modernidades: introducción", Otras modernidades. Historias, culturas, identidades, coord. por Saurabh Dube e Ishita Banerjee (México, D.F.: El Colegio de México, 2011) 23 .

${ }^{85}$ Arnold Bauer, Somos lo que compramos...,208. Sanders demuestra que los sectores subalternos lucharon por su reconocimiento como ciudadanos a través de varios mecanismos de negociación, sobre todo durante el periodo liberal, por lo cual la nación no fue una comunidad imaginada solo por las elites, con lo cual refuta a B. Anderson. Véase: James Sanders, Contentious Republicans..., 57.

${ }^{86}$ David Howes, Cross-cultural consumption ..., 1-15.

${ }^{87}$ El mercado de factores internos y externos de las economías de exportación incluyen los mercados de tierra y mano de obra, políticas monetarias, fiscales, comerciales, transportes, tecnología, las instituciones, el crecimiento de la población y la industrialización. Véase Colin Lewis, "Economías de exportación". Dicho mercado de fatores debería servir para construir una "biografía de los objetos" como lo propone Arjun Appadurai, "Introducción: Las mercancías y la política del valor" ..., 57.

${ }^{88}$ Sobre el comercio y la región suroccidental en la segunda mitad del siglo XIX tratará mi tesis doctoral que se encuentra en proceso de formulación.
} 
Finamente, no hay que olvidar que el consumo de bienes importados sólo se puede analizar dentro de la tupida y compleja red de poderes locales, regionales y transatlánticos, con sus rupturas y continuidades, con sus convulsiones, regresiones y estatismos. Preguntarse por ¿una modernización para quién y qué significados tuvo el consumo de importaciones?, es tan sólo una manera de entender que el consumo es una experiencia que va más allá del simple intercambio de objetos y que la elección de lo que se compra no se limita al precio y la capacidad económica del consumidor. Explorar sus significados, preguntarse por los discursos y analizar los medios que hicieron posible el intercambio, supone abordar el problema por sus profundidades y no por sus superficies.

\section{Bibliografía}

\section{Fuentes Primarias}

\section{Archivo}

Archivo General de la Nación(AGN), Sección República(SR), Aduanas Buenaventura.

Archivo Histórico de Cali (AHC), Notaria Primera.

Archivo Manuel María Buenaventura. (BLAA), Sala Raros y Manuscritos.

Archivo Richard Hyland, Universidad de los Andes. Oficina de Administración documental (OAD).

Archivo del Patrimonio Fotográfico y Fílmico del Valle del Cauca, Biblioteca Departamental Jorge Garcés Borrero (BDJGB).

Archivo Manuelita S.A.

\section{Publicaciones periódicas}

El ferrocarril, febrero de 1878 - diciembre de 1896, Biblioteca Luis Ángel Arango (BLAA), Hemeroteca.

El Correo del Valle. Periódico literario, industrial y noticioso, 1897, Biblioteca Luis Ángel Arango (BLAA), Sala Raros y Manuscritos.

El Cauca. Periódico literario dedicado a la juventud, 1875 Biblioteca Luis Ángel Arango (BLAA), Hemeroteca.

El trabajo. Comercio en general, ciencias, artes, literatura, industria y avisos, 1891. Biblioteca Nacional de Colombia, digital. 
Una modernización importada. Consumo de artículos extranjeros en el Valle del Cauca...

\section{Documentación primaria impresa}

Informe del Ministerio de Hacienda de la República de Colombia al Congreso Constitucional de 1892. Bogotá: Imprenta la Nación, 1892.

Informe del Ministerio de Hacienda de la República de Colombia al Congreso Constitucional de 1894. Ministro Pedro Bravo. Bogotá: Imprenta de Medardo Rivas, 1894.

"Informe de encargado de la Sección $2^{\circ}$ de Aduanas por el Ministro Manuel Esguerra, al Ministerio de Hacienda de la República de Colombia en 1896", Informe del Ministerio de Hacienda de la República de Colombia al Congreso Constitucional de 1896. Bogotá: Imprenta de Vapor de Zalamea, 1896.

Informe del Ministerio de Hacienda de la República de Colombia al Congreso Constitucional de 1898. Bogotá: Imprenta Eduardo Espinoza, 1898.

Isaac, Jorge. María. Bogotá: Plantea, 2013.

Memoria del Secretario de Hacienda Felipe Angulo dirigida al Presidente de la Unión en el año 1885. Bogotá: Imprenta de la Luz, 1885.

Mollien, Gaspar. "Por el Dagua hacia el Chocó", Viajeros extranjeros en Colombia, siglo XIX. Cali: Carvajal, 1970.

Palau, Lisímaco. Directorio General de Colombia. Comercial, Geográfico, Administrativo y Estadístico. Bogotá: Imprenta Nacional, 1898.

Rivera, Luciano. Impresiones y recuerdos, t. I y II. Bogotá: Librería Nueva, 1897.

\section{Fuentes secundarias}

\section{Libros}

Almario, Óscar. La configuración moderna del Valle de Cauca, Colombia, 18501940. Espacio, poblamiento, poder y cultura. Cali: CECAN Editores, 1994.

Almario, Óscar. La invención del suroccidente colombiano (Medellín: Universidad Pontificia Bolivariana, Concejo de Medellín, Corporación Instituto Colombiano de Estudios Estratégicos, 2005).

Arroyo, Jairo Henry. Historia de las prácticas empresariales en el valle del Cauca. Cali: Universidad del Valle, 2006.

Bauer, Arnold. Somos lo que compramos. Historia de la cultura material de América Latina. México: Taurus, 2002. 
Bourdieu, Pierre. La distinción. Criterios y bases sociales del gusto. Bogotá: TaurusSantillana, 1998.

Buriano, Ana. El "espíritu nacional” del Ecuador católico: artículos selectos de El Nacional, 1872-1875. México: Instituto Mora, 2011.

Colmenares, Germán. Cali, terratenientes y comerciantes. Siglo XVIII. Cali: Universidad del Valle, 1975.

Corral Bustos, Adriana. Estrategias de asociación para la inversión. El desarrollo del sistema de financiación en San Luis Potosí entre 1850-1900. San Luis Potosí: El Colegio de San Luis, 2017.

Dávila, Carlos (Comp.) Empresas y empresarios en la historia de Colombia, siglos $X I X-X X$. Bogotá: Uniandes, Norma, 2003.

Douglas, Mary y Isherwood, Baron. El mundo de los bienes. Hacia una antropología del consumo. México: Grijalbo, 1990.

Eder, Phanor. El fundador Santiago M. Eder. Bogotá: Flota Mercante Grancolombiana, 198.

Elías, Norbert. El proceso de la civilización. Investigaciones sociogenéticas y psicogenéticas. Colombia: Fondo de Cultura Económica, 1997.

Fernández Sebastián, Javier y Capellán, Gonzalo (coord.). Lenguaje, tiempo y modernidad. Ensayos de historia conceptual. España: Globo Editores, 2011.

García, Víctor. Remedios secretos y drogas heroicas: historia de los medicamentos en Antioquia 1900-1940. Medellín: Universidad Nacional de Colombia, 2008.

Granados, Aimer. Jurisdicción territorial, discurso modernizador y virtud cívica en Cali, 1880- 1915. Cali: Imprenta Departamental del Valle, 1996.

Howes, David. Cross-cultural consumption: global markets, local realities. Londres: Routledge, 1996.

Hyland, Richard. Sociedad y economía en el Valle del Cauca. El crédito y la economía, 1851-1880, t. IV. Bogotá: Banco Popular, 198.

Jaramillo, Jaime. El pensamiento colombiano en el siglo XIX. Bogotá: CESO, Uniandes, ICANH, Alfaomega, 2001.

Llorca Jaña, Manuel. The British textile trade in South America in the nineteenth century. Cambridge: Cambridge University Press, 2012. 
Una modernización importada. Consumo de artículos extranjeros en el Valle del Cauca...

Martínez, Frédéric. El nacionalismo cosmopolita. La referencia europea en la construcción nacional de Colombia, 1845-1900. Bogotá: Banco de la Republica, IFEA, 2001.

McGreevey, William Paul. Historia económica de Colombia, 1830-1930. Bogotá: Universidad de los Andes, 2015.

Miranda, Néstor. "Apuntes para la historia de la medicina en Colombia", Ciencia. Tecnología y Desarrollo, vol. 8. N. ${ }^{\circ}$ 1-4. Bogotá, enero-diciembre, 1984.

Ocampo, José Antonio. Colombia y la economía mundial 1830-1910. Bogotá: Tercer Mundo Editores, 1984.

Orlove, Benjamin, (Editor). The allure of the foreign: imported goods in postcolonial Latin America. Ann Arbor: University of Michigan Press, 2000.

Palacios, Marco. La clase más ruidosa y otros ensayos sobre politica e historia. Bogotá: Norma, 2002.

Pedraza, Zandra. En Cuerpo y alma: visiones del progreso y la felicidad. Bogotá: Universidad de los Andes. 1999.

Quiroga, Sebastián. Cultura líquida: transformación en el consumo de bebidas alcohólicas en Bogotá, 1880- 1930. Bogotá: Universidad Javeriana, 2018.

Rydell, Raymond. Cape Horn to the Pacific. The rise and decline of an ocean highway. Berkeley and Los Angeles: University of California Press, 1952.

Romero, Arturo. Historia de la medicina colombiana siglo XIX. Colombia: Universidad de Antioquia, 1996.

Sanders, James. The Vanguard of the Atlantic World: Creating Modernity, Nation and Democracy in Nineteenth Century Latin America. Durham: Duke University Press, 2014.

Sanders, James. Contentious Republicans: Popular Politics, Race, and Class in Nineteenth-Century Colombia. Durham: Duke University Press, 2004.

Sánchez, Hugues y Santos, Adriana (Ed.) Buscando el crecimiento económico. Mercado de factores, industrialización y desarrollo económico en Cali y el Valle del Cauca, 1900-1950. Cali: Universidad del Valle, 2018.

Safford, Frank. El ideal de lo práctico: el desafio de formar una élite técnica y empresarial en Colombia. Bogotá: El Áncora Editores, 1898. 
Safford Frank y Palacios, Marco. Colombia: país fragmentado sociedad dividida, su historia. Bogotá: Norma, 2002.

Valdivia Luis. Economía y espacio: en la Valle del Cauca, 1850 a 1930. Cali: Universidad del Valle, 1992.

Valencia Llano, Alonso. Empresarios y politicos en el Estado Soberano del Cauca, 1860-1895. Cali: Universidad del Valle, 1993.

Wallerstein, Immanuel. El moderno sistema mundial, tomo I. México: Siglo XXI Editores, 1979.

\section{Capítulos de libros}

Arjun Appadurai, “Introducción: Las mercancías y la política del valor", La vida social de las cosas. Perspectiva cultural de las mercancías. México: Grijalbo, 1991.

Artehortúa, Adolfo. “Buga en la Regeneración”, Estudios sobre la Regeneración, ed. por Lenín Flórez y Adolfo Artehortúa. Cali: Imprenta Departamental, 1987.

Dube, Saurabh “Otras modernidades: introducción”, Otras modernidades. Historias, culturas, identidades, coord. Saurabh Dube e Ishita Banerjee. México, D.F.: El Colegio de México, 2011.

García, Víctor. "Hábitos perniciosos y especialidades farmacéuticas: la legislación del medicamento en Colombia durante la primera mitad del siglo XX", Historia social y cultural de la salud y la medicina en Colombia, siglos XVI-XX, comp. Javier Guerrero, Luis Wiesner y Abel Martínez. Medellín: La Carreta y UPTC, 2010 .

García, Víctor y Márquez, Jorge. “estrategias publicitarias de medicamento en Colombia, 1850-1930", Higienizar, medicar, gobernar. Historia, medicina y sociedad en Colombia, Dir. Jorge Márquez. Medellín, Universidad Nacional de Colombia, 2004.

Kalmanovitz, Salomón. "El régimen agrario durante el siglo XIX en Colombia", Manual de Historia de Colombia, vol. 2. Bogotá: Procultura, 1982.

König, Hans-Joachim. "Ciudadano", Diccionario político y social del mundo iberoamericano. Iberconceptos I, dir. por Javier Fernández. Madrid: Fundación Carolina/Sociedad Estatal de Conmemoraciones Culturales/Centro de Estudios Políticos y Constitucionales, 2009.

Lewis, Colin. "Economías de exportación" Historia general de América Latina, vol. 7, Dir. Enrique Ayala. París, Unesco -Trotta, 2008. 
Londoño, Jaime. "Vapores y ferrocarril en la configuración de una región económica, 1874-1974”, Formas de modernización regional en el suroccidente colombiano. Cali: Facultad de Derecho y Ciencias Sociales, Universidad Icesi, 2013.

Maiguashca Guevara, Juan. "Encuadramientos espaciales e historia conceptual: Una reflexión autocrítica", en Horizontes de la Historia Conceptual ed. por Francisco Ortega, Rafael Acevedo y Pablo Casanova. Bogotá, Universidad Nacional de Colombia y grupo editorial G-9 de España, en prensa.

Pasez, Jean-Marie. "Historia de la cultura material", La historia y el oficio del historiador. Colectivo de autores franceses y cubanos. La Habana: Imagen contemporánea, 2002.

Palacios, Marco. "La regeneración ante el espejo liberal y su importancia en el siglo XX", La clase más ruidosa y otros ensayos de política e historia. Bogotá: Norma, 2002.

Safford, Frank. "El comercio de importación en Bogotá en el siglo XIX: Francisco Vargas, un comerciante de corte inglés", Empresas y empresarios en la historia de Colombia, siglos XIX-XX, Carlos Dávila. Comp. Bogotá: Uniandes, Norma, 2003.

Urrutia, Miguel. "Precios y salarios urbanos en el siglo XIX”, La economía del siglo $X I X$, ed. Adolfo Meisel y Teresa Ramírez. Bogotá: FCE, Banco de la República de Colombia, 2010.

\section{Artículos de revistas}

Colmenares, Germán. "El papel de la historia regional en el análisis de las formaciones sociales”, Ideología y Sociedad, n. ${ }^{\circ} 12$ (1975).

Colmenares, Germán. "El tránsito a sociedades campesinas de dos sociedades esclavistas en la Nueva Granada, Cartagena y Popayán, 1780-1850”, Huellas, n. ${ }^{\circ}$ 29 (1990).

Calhoun, Craig. "Nationalism and Ethnicity" Annual Reviews n. 19 (1995).

Noguera, Carlos Ernesto. "La higiene como política", Anuario Colombiano de Historia Social y de la Cultura, n. ${ }^{\circ} 25$ (1998).

Otero, Ana María. ““'Jeneros de gusto y sobretodos ingleses”: el impacto cultural del consumo de bienes ingleses por la clase alta bogotana del siglo XIX", Historia Crítica, n. ${ }^{\circ} 38$ (2009).

Palacios, Marco. "Modernidad, modernizaciones y ciencias sociales", Análisis político, n. $^{\circ} 23$ (1994). 
Pereira Fernández, Alexander. "Cachacos y guaches: la plebe en los festejos bogotanos del 20 de julio de 1910”, Anuario Colombiano de Historia Social y de la Cultura, vol. $38 \mathrm{n} .^{\circ} 1$ (2011).

Pinto, José J. y Granados, Óscar. “Más allá de Pamplona (Nueva Granada): circuitos cacaoteros del suroccidente durante la transición, 1790-1821", Revista de Historia Económica, Journal of Iberian and Latin American Economic History, Vol. 37, n. ${ }^{\circ}$ (2019).

Safford, Frank, “Acerca de las interpretaciones socioeconómicas de la política en la Colombia del siglo XIX: variaciones sobre un tema", Anuario Colombiano de Historia Social y de la Cultura, n. ${ }^{\circ} 13-14$, (1985).

Taracena Arriola, Arturo. "Propuesta de definición histórica para región”, Estudios de Historia Moderna y Contemporánea de México, n. ${ }^{\circ} 35$ (2008).

\section{Tesis}

Otero, Ana María. "From fashionable pianos to cheap white cotton: Consuming foreign commodities in nineteenth-century Colombia". Dissertation Ph.D. Modern History (Latin America), University of Oxford, 2011. 